\title{
BALANCE DE LA MOCIÓN DE CENSURA CONSTRUCTIVA EN UN PARLAMENTO FRAGMENTADO
}

\author{
PIEDAD GARCÍA-ESCUDERO MÁRQUEZ \\ Catedrática de Derecho Constitucional \\ Universidad Complutense de Madrid
}

\section{SUMARIO}

I. Introducción. La moción de censura en su contexto II. Novedades en el funcionamiento del Congreso III. La dificultad de legislar, salvo por decreto-ley IV. Vicisitudes presupuestarias V. El control al Gobierno, también por sus aliados... y por el Senado VI. La función de nombramiento VII. Epílogo: turbulencias durante la disolución y resultados electorales VIII. Conclusiones: de cara al futuro

\section{INTRODUCCIÓN. LA MOCION DE CENSURA EN SU CONTEXTO}

En junio de 2018 se produjo un hecho insólito en nuestra historia constitucional, la aprobación de una moción de censura como colofón de un periodo caracterizado por numerosos acontecimientos inéditos, que requirieron de la aplicación e interpretación de nuevos preceptos constitucionales. El fin del bipartidismo genera un Congreso de los Diputados fragmentado que dificulta la investidura de un Presidente del Gobierno, con dos intentos fallidos en dos legislaturas (separadas por las primeras elecciones convocadas en aplicación del artículo 99.5 CE) que comparten un largo periodo de gobierno en funciones, desde las elecciones celebradas el 20 de diciembre de 2015 hasta la investidura de Mariano Rajoy ya en la XII legislatura, el 29 de octubre de 2016, al borde de la expiración del plazo de dos meses desde la primera votación que habría supuesto unas terceras elecciones generales en un año ${ }^{1}$.

1 El desarrollo de la XI y los inicios de la XII legislatura hasta llegar a la investidura pueden verse en P. García-Escudero Márquez, «Actividad legislativa del Parlamento con un Gobierno en funciones», en 
La legislatura abierta con las elecciones de 26 de junio de 2016, aparte de las dificultades para investir a un Presidente del Gobierno, pasará a la historia constitucional por ser la primera en la que se aprueba una moción de censura, hasta ahora presentada de forma testimonial en unas pocas ocasiones ${ }^{2}$, sin grandes perspectivas de éxito. Por primera vez se pondrán de manifiesto en la práctica las consecuencias de la aprobación de una moción de censura constructiva —adjetivo con el que se pretende dotar de estabilidad al Gobierno nacido de la moción-, que supone un cambio de signo político del Ejecutivo en el curso de una legislatura ${ }^{3}$.

La peculiaridad más significativa de este estreno reside en la composición del Congreso de los Diputados, la cual ya había provocado alteraciones esenciales en el funcionamiento del sistema en la primera mitad de la legislatura, con el Gobierno del Partido Popular ${ }^{4}$, que pueden resumirse de la forma siguiente:

- el fin del bipartidismo no afecta sólo a la composición del Pleno y de las comisiones, sino también a la Mesa de la Cámara y a las Mesas de las comisiones, órganos de gobierno en los que el Ejecutivo no siempre cuenta con mayoría, lo que introduce diferencias respecto del tradicional funcionamiento de nuestro régimen parlamentario, siendo un ejemplo de las disfunciones que se producen los conflictos con la Mesa del Congreso en materia de proposiciones de ley presupuestarias, que llegan hasta el Tribunal Constitucional ${ }^{5}$

- tras un largo período de Gobierno en funciones, impedido para ejercer la iniciativa legislativa mediante proyectos $\mathrm{de} \mathrm{ley}^{6}$, tampoco después de la

E. Aranda Alvarez (coord.), Lecciones constitucionales de 314 días con el Gobierno en funciones, Tirant lo Blanch, Valencia, 2017, pp. 237 y ss., así como en I. GimÉNEZ SÁNCHEZ, «La actividad desarrollada por las Cortes en la situación de legislatura fallida y de Gobierno en funciones», REDC, n. ${ }^{\circ} 109,2017$, pp. 215 y ss.

2 En tres ocasiones: contra A. Suárez en 1980, F. González en 1987 y, en la misma legislatura que examinamos, M. Rajoy. Esta última fue presentada por 36 diputados del Grupo UP-ECP-EM el 19 de mayo de 2017, con P. Iglesias Turrión como candidato a la Presidencia del Gobierno.

3 Sobre la moción de censura en la Constitución de 1978 pueden consultarse los trabajos de J. R. MoNtero Gibert (1979), F. Santaolalla López (1980), E. Vírgala Foruria (1988), M. Revenga Sánchez (1988), P. Mellado Prado (1988), M. Sánchez De Dios (1992), F. Fernández Segado (1998), C. Elías Méndez (2005), F. Simón Yarza (2015), J. García Fernández (2017), E. GonZÁlez Hernández (2018).

4 Sobre las cuestiones planteadas por un Congreso fragmentado frente a un Gobierno en minoría en la primera parte de la legislatura, P. GArCíA-Escudero Márquez, «Un nuevo Parlamento fragmentado para los 40 años de la Constitución», Revista de Derecho Político, n. ${ }^{\circ}$ 101, 2018, pp. 67-98. Algunas de estas cuestiones se resumen y completan a continuación, como contexto en el que se produce la moción de censura.

5 Conflictos entre órganos constitucionales resueltos por SSTC 34/2018 y 44/2018; véanse también las posteriores SSTC 94/2018, 139/2018 y 17/2019, dictadas en sendos recursos de amparo contra decisiones de la Mesa del Congreso que aceptaron la disconformidad del Gobierno con la tramitación de proposiciones de ley (el llamado veto presupuestario).

6 La problemática planteada por el dilatado período de gobierno en funciones, en P. GARCía-EscuDero Márquez, «Gobierno en funciones y función legislativa», Cuadernos Manuel Giménez Abad, n. ${ }^{\circ} 11$, pp. 106 y ss., así como M. CARrillo, «Las atribuciones del Gobierno en funciones», REDC, n. ${ }^{\circ}$ 109, 2017, pp. 121 y ss. 
investidura la perspectiva es muy halagüeña para la iniciativa gubernamental, siendo incierto su resultado ${ }^{7}$. En consecuencia, el Gobierno se autolimita, siendo escaso el número de proyectos presentados y de leyes aprobadas, sin que tampoco constituya alternativa la aprobación de decretos-leyes $\left(29,30\right.$ desde las elecciones de $\left.2016^{8}\right)$, de cuya convalidación se duda: uno no es convalidado, supuesto absolutamente excepcional que sólo se había producido dos veces en nuestra democracia constitucional, una de ellas por error ${ }^{9}$.

- si legislar planteaba dificultades, hasta el punto de que nos preguntábamos si era posible gobernar sin legislar, tampoco sería fácil la tramitación de los Presupuestos Generales del Estado. Los de 2016 se aprobaron precipitadamente en otoño de 2015 (Ley 48/2015, de 29 de octubre), antes de la disolución que daría lugar a las elecciones de 20 de diciembre; los de 2017 se retrasarían hasta junio del año de su vigencia (Ley 3/2017, de 27 de junio $)^{10}$, con la consiguiente prórroga previa de los anteriores. La Ley de Presupuestos Generales para 2018 también llega con retraso, aprobándose por el Congreso el 23 de mayo de dicho año, sorprendentemente -y esta es una de las singularidades que rodean el acontecimiento- dos días antes de que se presente la moción de censura que sería aprobada una semana después ${ }^{11}$. Como spoiler conocido, adelantaremos que tampoco la iniciativa presupuestaria le resultaría sencilla al nuevo Gobierno salido de

7 Desde la investidura de Rajoy hasta el 1 de junio de 2018, el Gobierno había presentado 17 proyectos de ley (frente a 243 proposiciones de ley de grupos parlamentarios en el Congreso en veinte meses de legislatura). De ellos, antes de la moción de censura — con el nuevo Gobierno otros 8 proyectos del anterior se aprobarían como leyes - sólo 9 (si contamos la Ley de Presupuestos pendiente de tramitación en el Senado), más uno procedente de un decreto-ley convalidado, se habían convertido en leyes; en el mismo período y con la misma inclusión de iniciativas ya aprobadas por el Congreso, se aprobaron 10 leyes procedentes de proposiciones. Salvando las dos leyes de presupuestos para 2017 y 2018 y las dos sobre concierto y cupo vasco, el resto de las leyes procedentes de proyectos eran transposición de directivas o cumplimiento de reglamentos europeos. Las cifras son elocuentes si se tiene en cuenta que el Gobierno — titular de la iniciativa prioritaria y prevalente en el régimen parlamentario - antaño presentaba el 90 por ciento de las iniciativas legislativas, el 90 por ciento de las cuales se convertían en ley.

8 Para comprender correctamente el significado de este número ha de tenerse en cuenta que, de los 29 decretos-leyes aprobados, varios responden a la necesidad de remediar la no aprobación de los Presupuestos Generales del Estado, otros a atender necesidades sociales (deudores hipotecarios), daños por temporales o sequía, o compromisos internacionales y transposición de directivas.

9 El precedente de rechazo voluntario de la convalidación de un decreto-ley — que implica su inmediata derogación - se remonta a 1979; existe otro supuesto de no convalidación por error en 2006. Estos datos muestran lo inusual de que, en nuestro régimen parlamentario antes cuasibipartidista, el Congreso no convalidara un decreto-ley. En la XII legislatura ocurrirá en dos ocasiones, una con cada Gobierno.

10 Para las circunstancias de la tramitación y negociación, voto a voto, de estos presupuestos, véase $\mathrm{P}$. García-Escudero MárqueZ, «Un nuevo Parlamento fragmentado para los 40 años de la Constitución», cit., pp. 84-86.

11 Tras la aprobación de la moción de censura, el Proyecto continuó su tramitación en el Senado, siendo definitivamente aprobado por el Congreso de los Diputados el 28 de junio de 2018 (Ley 6/2018, de 3 de julio, de Presupuestos Generales del Estado para 2018). 
la censura, pues el rechazo del Proyecto de Ley de Presupuestos para 2019 el 13 de febrero de ese año, mediante la aprobación de enmiendas de totalidad de devolución, provocaría el fin de la legislatura por disolución de las Cámaras y convocatoria de elecciones para el 28 de abril.

- en un Congreso fragmentado con un Gobierno en minoría, la visibilidad de los nuevos partidos se persigue mediante un nuevo uso de los instrumentos de control, con la proliferación de comisiones de investigación, en particular respecto de actuaciones del Gobierno anterior del mismo signo político que el ejerciente, y el uso habitual de las reprobaciones de ministros o incluso de otras autoridades. También cuenta la primera mitad de la legislatura con una moción de censura fracasada, calificada de mediática incluso por sus autores, y reforzada por la apelación a la movilización ciudadana («la moción de censura se gana en la calle»).

- el fin del bipartidismo y sus cuotas inherentes planteó asimismo problemas en la función de nombramiento, con experimentos cuyo fracaso veríamos en el siguiente periodo (Consejo de Administración de RTVE) o la permanencia en funciones del Adjunto al Defensor del Pueblo desde julio de 2017, por no anticipar los problemas que se plantearían respecto de algún otro órgano.

En el contexto del panorama así dibujado, correspondiente a la primera parte de la legislatura, que alcanza algo más de año y medio de gobierno en plenas facultades (desde la investidura el 29 de octubre de 2016 hasta el 1 de junio de 2018), la presentación —y éxito- de una segunda moción de censura se define por su carácter repentino en varios aspectos:

- en su presentación, el 25 de mayo de 2018, apenas dos días después de que el Gobierno obtuviera en el Congreso la mayoría suficiente para la aprobación de los presupuestos generales del Estado. El acontecimiento detonante fue una sentencia de la Sala de lo Penal de la Audiencia Nacional en la que se condenaba al Partido Popular como responsable a título lucrativo de una trama de corrupción y se formulaban algunas observaciones sobre sus actividades ${ }^{12}$.

- en su debate y votación, probablemente por voluntad del propio Presidente del Gobierno ${ }^{13}$, iniciándose el debate el 30 de junio y celebrándose

12 Véase la exposición de motivos de la moción de censura en BOCG Congreso, Serie D, n. ${ }^{\circ}$ 358, p. 3.

13 Según cuenta el Presidente investido P. SÁNCHEZ en Manual de resistencia (Península, 2019; según extracto publicado en El País el 17 de febrero de 2019), la Presidenta del Congreso le informó de las fechas del debate y votación el 28 de mayo. Frente a las especulaciones «sobre de qué modo la premura con que sucedió todo influyó en el resultado», Sánchez cree que «fue algo coyuntural con escasa influencia», siendo lo realmente relevante que «la Gürtel era la gota que colmó el vaso». No es la opinión de C. Campuzano (PdeCat), para el cual «la decisión de Ana Pastor de precipitar el debate fue un error clave. Si se alarga dos o tres semanas, se habría complicado. La clave es que [la moción] no fue negociada. Y que sólo se decidía si dejar o no a Rajoy en el Gobierno (C. E. Cué, «Un año de la carambola que lo cambió todo», El País, 1 junio 2019. El autor concluye: 
la votación el 1 de junio, una semana después de su presentación, poco más de los cinco días de enfriamiento que exige el artículo 113.3 de la Constitución ${ }^{14}$.

Fue en el curso del debate cuando se hizo patente el giro del Grupo EAJPNV, respecto de su posición favorable al Gobierno una semana antes en la votación de los presupuestos, hasta apoyar ahora la moción y hacer posible el resultado positivo: 180 votos a favor, 169 en contra y 1 abstención ${ }^{15}$, superando en cuatro votos la mayoría absoluta necesaria.

El éxito de la moción de censura constructiva no supone esta vez, como cabría pensar en un sistema cuasibipartidista, que una parte cohesionada de la Cámara se impone a otra, asimismo homogénea o cohesionada. En este caso, al Gobierno de minoría del Partido Popular, cuyo Grupo cuenta con 134 diputados, se ha opuesto una constelación de partidos de distinto signo, capaz de construir un Presidente, pero cuya unión inestable se constataría en los meses siguientes, teniendo aquél asegurados sólo los 84 votos de los diputados de su grupo parlamentario ${ }^{16}$.

Así se inicia la segunda parte de la legislatura que examinamos en este trabajo, en cuanto a los efectos que la moción de censura constructiva ha tenido en un Parlamento fragmentado y en la inestabilidad gubernamental que abocaría finalmente a unas elecciones anticipadas ${ }^{17}$. No bastarán en estos meses las

fue una carambola tan rápida que nadie pudo controlarla). En el mismo sentido, según L. Méndez, la dirección del PNV sostiene que, de haberse convocado el Pleno una semana después, la apertura de negociación con los independentistas catalanes habría encallado y la moción habría fracasado ( Providencia y maldición. Un año después de la moción de censura a Rajoy y la llegada de Sánchez a La Moncloa», El Mundo, 2 junio 2019).

14 En su intervención, el candidato a Presidente pidió reiteradamente al Presidente Rajoy que dimitiera para acabar con la tramitación de la moción de censura (como es sabido, la disolución de las Cámaras le estaba vedada por aplicación del art. 115.2 CE). La posibilidad de dimisión que —entendemos— se le abría al Presidente del Gobierno es considerada por A. RuIz Robledo un fraude constitucional, entre otras razones porque ello le permitiría seguir en funciones hasta que se invistiera otro candidato ( Rajoy no tenía el botón nuclear», Diario del Derecho Iustel, 4 junio 2018). En el mismo sentido, D. Delgado Ramos, «Teoría y práctica de la moción de censura: notas críticas a propósito de la experiencia reciente», RGDC, n. ${ }^{\circ}$ 29, 2019 , p. 19.

15 Votaron a favor los diputados de los Grupos Socialista (84), Confederal UP-ECP-EM (67), ERC (9), PNV (5), PDeCat. (8), Compromìs (4), EH Bildu (2), Nueva Canarias (1); en contra, Grupo Popular (134), Ciudadanos (32), UPN (2), Foro (1). Se abstuvo la diputada de Coalición Canaria.

16 Las conclusiones que extrae F. Simón YARZA ( «De la investidura convulsa a la moción de espíritu destructivo», REDC, n. ${ }^{\circ} 116,2019$, pp. 119-120) de la única ocasión en que triunfó una moción de censura en la República Federal Alemana (contra H. Schmidt y en favor de H. Kohl) son plenamente aplicables al supuesto español: que ni siquiera la correcta aplicación de las reglas que configuran la moción constructiva es suficiente para asegurar la gobernabilidad y que un jefe del ejecutivo que carece de una mayoría lo suficientemente sólida - sea del propio partido, sea en coalición con otros - encuentra serias dificultades para gobernar en un régimen parlamentario; en tales casos, puede resultar apropiado que un gobierno debilitado persiga la disolución anticipada del parlamento para proceder a nuevas elecciones. Este ejemplo alemán (junto con otros intentos no logrados) muestra «que el carácter constructivo de la moción constituye un remiendo normativo para evitar la inestabilidad política, si bien no garantiza por sí solo el buen funcionamiento del régimen parlamentario».

17 Desenlace que erróneamente vaticiné respecto del Gobierno menos minoritario anterior, para el que auguraba «una paralización (legislativa, pero no sólo)..., que en suma, tras el paso dificultoso del tiempo, no 
frecuentes apelaciones a la mayoría que votó la moción de censura, llamando a la unidad a unos socios de gobierno «a la carta» que pueden reprobar ministros o no convalidar decretos-leyes, a la vez que se desarrollan en paralelo las postrimerías del proceso de independencia de Cataluña (incluidas sus consecuencias judiciales) y de la aplicación del artículo 155 de la Constitución. En definitiva, el rechazo de los presupuestos habrá de ser visto también bajo ese prisma.

Pretendemos hacer balance del periodo que se extiende desde la moción de censura hasta la disolución y compararlo con el también dificultoso periodo anterior, así como con otras legislaturas, para en último término mostrar cómo el fin del bipartidismo ha influido en el funcionamiento de las relaciones Gobierno-Parlamento en nuestro régimen parlamentario, sin que se haya conseguido asimilar suficientemente una cultura del pacto que permita la adaptación a las nuevas circunstancias ${ }^{18}$.

En este período, en el que analizaremos el desarrollo de las funciones constitucionales de las Cortes Generales, podremos constatar la dificultad de gobernar con unas mayorías cambiantes y la utilización del decreto-ley como instrumento legislativo ordinario; los reveses legislativos y presupuestarios que experimenta un Gobierno apoyado por 84 diputados (rechazo de la senda del déficit, no nos olvidemos del Senado con mayoría del principal grupo de la oposición; decreto-ley no convalidado), así como, al final del único período de sesiones completo de mandato, el fantasma de los resultados electorales y postelectorales en Andalucía $^{19}$, que en cierto modo provocan la huida hacia adelante con la presentación del proyecto de ley de presupuestos sin garantías de aprobación y, en última instancia, la disolución anticipada.

Con carácter previo al examen de las funciones de las Cámaras, haremos una breve referencia a modificaciones en el funcionamiento del Congreso de los Diputados fragmentado a partir de la moción de censura.

\section{NOVEDADES EN EL FUNCIONAMIENTO DEL CONGRESO}

Hemos apuntado ya cómo la XII legislatura aporta novedades en la organización y funcionamiento de la Cámara, tales como la composición de la Mesa de

conduce sino a la disolución anticipada» (P. GARCía-Escudero MÁrQUEZ, «Un nuevo Parlamento fragmentado para los 40 años de la Constitución», cit., p. 97).

$18 \mathrm{Al}$ menos en la política nacional. Para J. Fernández Albertos ( «onvivir con el multipartidismo», El País, 18 abril 2019), en sólo cuatro años hemos normalizado el multipartidismo con participación de Cs y Podemos en Gobiernos regionales y defensa en sus campañas de partidos de coalición, aunque son motivos para la preocupación que la campaña gire más en torno a los vetos y políticas de alianzas de cada uno que sobre sus propuestas y prioridades. La situación ofrece nuevos matices tras las elecciones autonómicas y municipales de 2019 (ver nota 87).

19 La opinión de G. TorTella sobre la influencia de los resultados electorales de Andalucía y la irrupción de Vox en la posición del Gobierno sobre el tema catalán en «La verdad sobre el 'caso Sánchez'», El Mundo, 1 marzo 2019. 
la Cámara y de las comisiones, que adoptan decisiones importantes para la actividad parlamentaria.

En la segunda parte de la legislatura, la primera novedad a reseñar es que el Presidente del Gobierno no es diputado. Cierto que no es un requisito constitucional, y que de hecho hubo un candidato a Presidente en otra moción de censura, no investido, que ostentaba la condición de senador (Hernández Mancha, 1987). Lo curioso es que Pedro Sánchez había sido elegido diputado al inicio de la legislatura, pero renunció al escaño el 29 de octubre de 2016, el mismo día en que su Grupo se abstendría en la investidura de Rajoy.

No siendo diputado el Presidente, como tampoco la mayor parte de los ministros (muchos diputados de su Grupo no formaban parte de sus afectos), se produce la renuncia al escaño de los tres que ostentaban tal condición (Ábalos, Batet y Robles, Ministro de Fomento y Ministras de Política Territorial y Función Pública, y Defensa, respectivamente) con fecha 15 de junio de 2018. Un banco azul sin miembros de la Cámara es un acontecimiento inédito más, que por otro lado visibiliza que se trata de un Gobierno no salido de unas elecciones.

La segunda novedad deriva de que, por primera vez, el Presidente no es el líder del Grupo que cuenta con mayor número de escaños. A diferencia del Reglamento del Senado, cuyo artículo 86 establece que la intervención de los portavoces, tanto en los Plenos como en las comisiones, se efectuará en orden inverso al número de componentes de los respectivos grupos parlamentarios, el artículo 75.4 del Reglamento del Congreso sólo dispone que todos los turnos generales de intervención de los grupos parlamentarios serán iniciados por el Grupo Parlamentario Mixto. La práctica, no obstante, es también en esta Cámara el orden inverso de intervención, comenzando por el Grupo Mixto (que por otra parte cuenta con 19 miembros en esta legislatura, más que los Grupos Vasco y Esquerra Republicana juntos), salvo en determinados debates relevantes en Pleno — como las comparecencias del Presidente del Gobierno o los relacionados con la confianza-, los cuales se inician por el principal grupo de la oposición, interviniendo a continuación los restantes grupos por orden de tamaño y finalmente el grupo que apoya al Gobierno, que hasta ahora coincidía siempre con el de mayor número de diputados.

Dado que, a partir de la moción de censura, el Grupo que apoya al Gobierno no es el más numeroso, se planteó cuál debía ser el portavoz que cerrara los debates en Pleno y en comisión, si el del Grupo Socialista, de apoyo al Gobierno, o el del Popular, mayoritario. Se optó por no modificar la práctica del orden inverso de grupos en función de la importancia numérica, cerrando los debates el Grupo Popular. En el supuesto de comparecencias del Presidente del Gobierno y otros de especial relevancia, se mantiene el orden de mayor a menor de los grupos parlamentarios, con la intervención final del portavoz del Grupo Socialista ${ }^{20}$.

20 Véase, por ejemplo, DSCD n. ${ }^{\circ}$ 183, de 27 de febrero de 2019. Con la excepción del primer debate de este carácter tras la moción de censura, celebrado el 27 de junio de 2018. 


\section{LA DIFICULTAD DE LEGISLAR, SALVO POR DECRETO-LEY}

\section{La iniciativa del Gobierno y el gobierno por decreto-ley}

Planteada la situación del Gobierno en minoría en el Congreso de los Diputados y la mayoría inestable — pues no lo es a todos los efectos- que surge de la moción de censura, examinaremos el modo en que ello repercute en la función legislativa.

El nuevo Gobierno presenta 6 proyectos de ley hasta el fin de la legislatura (nueve meses), uno aprobado en Consejo de Ministros posterior al anuncio de la disolución ${ }^{21}$, que se produjo el viernes siguiente a la derrota sobre los presupuestos (15 de febrero). Sólo uno de estos proyectos, el primero presentado, se convertiría en ley $^{22}$. El número total de leyes aprobadas en el período examinado, es de $22^{23}$, de ellas 9 procedentes de proyectos del Gobierno anterior ${ }^{24}$.

Este número contrasta fuertemente con el de decretos-leyes aprobados en el mismo período, que asciende a 32 (4 de ellos aprobados después del anuncio de disolución), a los que se añaden 3 aprobados cuando las Cámaras ya estaban disueltas; tanto los acordados después del anuncio — salvo uno- como los posteriores a la disolución (en total 6) serían convalidados el 3 de abril de 2019 por la Diputación Permanente, algo excepcional aunque previsto en la Constitución ${ }^{25}$. Si comparamos con el otro Gobierno de la legislatura, que no disponía de las mismas facilidades de convalidación, comprobamos que este aprobó menos decretos-leyes: 30 en veinte meses, uno cuando todavía estaba en funciones. En el segundo periodo, al igual que en el anterior, un decreto-ley no fue convalidado por el Congreso de los Diputados, quedando por tanto derogado ${ }^{26}$.

21 Sobre la reforma educativa, para dejar constancia del trabajo realizado y gobernar hasta el último día, en palabras de la Ministra del ramo y portavoz del Gobierno.

22 Proyecto de ley de mejora de las condiciones para el desempeño de la docencia y la enseñanza en el ámbito de la educación no universitaria, aprobado definitivamente por el Pleno del Congreso de los Diputados el 21 de febrero de 2019 (Ley 4/2019, de 7 de marzo).

23 Incluyendo las que estaban concluidas o a punto de concluir su tramitación antes de la moción, promulgadas en junio y julio de 2018: Leyes 3, 4, 5 y 6/2018, entre ellas la de presupuestos para 2018, como se ha señalado.

24 Véase nota 32.

25 En el conjunto de las legislaturas anteriores se convalidaron 40 decretos-leyes por la Diputación Permanente, siendo más numerosos en la legislaturas I (9) y IV (8), V y Constituyente (7), IX (5); 1 en las legislaturas X, VIII, VI y II y ninguno en la XI, VII y III. El Gobierno, tras la disolución, anuncia los «viernes sociales», en referencia a las medidas que acordará el Consejo de Ministros por decreto-ley, lo que motiva reclamaciones ante la Junta Electoral Central por parte de PP y Cs sobre las ruedas de prensa posteriores a las reuniones del Consejo. La JEC adopta sendos acuerdos desestimatorios en 11 de marzo de 2019, por no denunciar aquéllos conductas prohibidas y referirse a ruedas de prensa futuras con carácter meramente hipotético.

26 Real Decreto-ley 21/2018, de 14 de diciembre, de medidas urgentes en materia de vivienda y alquiler. La convalidación fue rechazada por 103 votos a favor, 243 en contra y 1 abstención. La portavoz del Grupo UP-ECP-EM, determinante para el resultado, puntualizó que el voto «no busca humillar [al Gobierno], no busca hacerles daño ni mucho menos pretende deshacer la mayoría de progreso que se generó en la moción de censura» (Diario de Sesiones 22 enero 2019, n. ${ }^{\circ}$ 175, p. 16). 
No vamos a entrar en la polémica sobre el presupuesto habilitante que en cada caso legitimaba el recurso al decreto-ley, instrumento legislativo constitucionalmente previsto para situaciones de extraordinaria y urgente necesidad. Nos detendremos más adelante, al referirnos a la función de nombramiento, en el primero de los aprobados, relativo al régimen jurídico aplicable al Consejo de Administración de RTVE y de su presidente ${ }^{27}$. Aquí nos interesa destacar el objetivo de este Real Decreto-ley, expuesto en su preámbulo, que también habla de «bloqueo parlamentario»: «resolver una situación provocada por la falta de cumplimiento por parte de las Cámaras» del mandato contenido en una ley anterior. La pregunta que se nos suscita en términos generales es la siguiente: ¿es legítimo que, con un Parlamento fragmentado, un Gobierno en minoría pueda llegar a sustituir a aquél en la función legislativa? ${ }^{28}$. Si habíamos alertado del riesgo de caer en un gobierno de Asamblea ${ }^{29}$ frente a un Ejecutivo minoritario, tampoco esta segunda solución a situaciones que parece no van a ser tan excepcionales en el futuro nos parece la más adecuada para el equilibrio de poderes.

Se dirá que la Cámara decide, mediante la convalidación, si el uso del decreto-ley es correcto o no. Aun así, el peligro es que, con la anuencia de una mayoría, se desvirtúe el verdadero sentido del decreto-ley y se convierta en un instrumento ordinario de legislación. Esta reflexión se ve corroborada por el hecho de que, en la legislatura que examinamos, se acordara la tramitación como proyecto de ley de 24 decretos-leyes, de ellos 19 procedentes del segundo Gobierno (uno convalidado la semana anterior a la disolución $)^{30}$. Cabría entender este dato como positivo, en el sentido de que la Cámara mantiene, a través de la tramitación posterior, sus facultades legislativas. Pero también cabe la interpretación contraria, esto es, que podría haberse tramitado un proyecto de ley con cierta celeridad sin necesidad de acudir al recurso extraordinario, sobre todo si tenemos en cuenta que de los así tramitados sólo uno (del primer periodo) se convertiría en ley ${ }^{31}$.

27 Real Decreto-Ley 4/2018, de 22 de junio, por el que se concreta, con carácter urgente, el régimen jurídico aplicable a la designación del Consejo de Administración de la Corporación RTVE y de su Presidente.

28 En este sentido, afirma F. Carreras («La demolición ha empezado», El País 21 noviembre 2018): los decretos-leyes no están a disposición del Gobierno de turno para evitar que las leyes se elaboren y aprueben en las Cortes Generales; están para otra cosa.

29 Advertía M. Aragón Reyes («Legislatura fallida e investidura convulsa. Análisis y consecuencias», REDC, n. ${ }^{\circ} 109,2017$, p. 33) frente a una deriva hacia un parlamentarismo de asamblea, que directamente destruye el régimen parlamentario, en el que debe existir una reserva de Gobierno (dirigir la política) y una reserva de Parlamento (controlar aquélla). Una oposición mayoritaria — decía el autor citado— no debe significar una constante obstrucción de la tarea del Gobierno; un Gobierno minoritario sin pactos sería incapaz de gobernar.

30 Sobre la cuestión de la tramitación de los decretos-leyes como proyectos de ley por la Diputación Permanente véase infra, apartado VII.

31 Ley 1/2018, de 6 de marzo, por la que se adoptan medidas urgentes para paliar los efectos producidos por la sequía en determinadas cuencas hidrográficas y se modifica el texto refundido de la Ley de Aguas, aprobado por Real Decreto legislativo 1/2016, de 20 de julio (procedente del Real Decreto-ley 10/2017, de 9 de junio). 


\section{La tramitación parlamentaria de las iniciativas legislativas}

La actividad legislativa tras la moción de censura se agiliza. Como no podía ser de otro modo, se continúan tramitando proyectos de la época anterior (ya se ha señalado que 9 de las leyes promulgadas provenían de proyectos del anterior Gobierno, casi todos ellos relativos a compromisos europeos ${ }^{32}$ ) y se desbloquean proposiciones.

Recordemos que entre los problemas generados por la carencia de mayoría en la Mesa del Congreso por ninguno de los dos Gobiernos se encuentra que no queda en manos del Grupo que le apoya la decisión sobre la ampliación de plazos de enmiendas ${ }^{33}$, lo que hace que las iniciativas puedan dormir eternamente el sueño de los justos. En último término, es el voto de los miembros de la Mesa pertenecientes al Grupo Ciudadanos el que decide en ambos periodos, y en un momento dado este Grupo anuncia que dejará de apoyar determinadas ampliaciones indefinidas ${ }^{34}$.

Si hasta la moción de censura se habían presentado 243 proposiciones de ley de grupos parlamentarios en el Congreso de los Diputados, al final de la legislatura serán 333. Aunque sean pocas las que culminen su tramitación (15 leyes, 8 aprobadas antes de la moción de censura — dos de ellas cuando el Gobierno se hallaba en funciones, Leyes orgánicas $1 / 2019$ y 2/2019- y 7 después), en términos relativos son muchas respecto de los 17 proyectos convertidos en ley (más uno procedente de decreto-ley), a su vez en comparación con otras legislaturas ${ }^{35}$.

El incremento de la actividad legislativa se manifiesta, cuando empiezan a cerrarse los plazos de enmiendas, en la tramitación simultánea de cierto número de iniciativas en determinadas comisiones. Por tomar las dos más activas, Justicia

32 En materia de protección de datos personales, régimen económico y fiscal de Canarias, medio ambiente, información no financiera y diversidad, secretos empresariales propiedad intelectual y crédito inmobiliario (L.O. 3/2018 y Leyes 8/2018, 9/2018, 11/2018, 1/2019, 2/2019 y 5/2019, respectivamente), además de los proyectos que estaban prontos a concluir su tramitación, en materia de orden europea de investigación y presupuestos, Leyes 3/2018 y 6/2018.

33 Las ampliaciones de plazos de enmiendas, como de otros plazos, de conformidad con el artículo 91.1 RC, se acuerdan por la Mesa de la Cámara, cuyas decisiones se adoptan por mayoría, a la vista de las peticiones de ampliación presentadas por los grupos parlamentarios.

34 Ver La Vanguardia 30 octubre 2018 («Ciudadanos desbloquea otras 22 leyes»), coincidiendo con la toma en consideración en esa fecha de una Proposición de reforma del Reglamento presentada por el Grupo Socialista sobre limitación de las prórrogas de plazos de enmiendas a iniciativas legislativas, que caducó con el fin de la legislatura. La proposición admitía dos prórrogas a petición de algún grupo parlamentario, mientras que las ulteriores debían ser solicitadas por al menos dos grupos que representaran la mayoría absoluta de los miembros de la Cámara. La toma en consideración fue acordada por 178 votos a favor y 163 en contra (del Grupo Popular, Ciudadanos y 1 del Grupo Mixto).

35 Por ejemplo, en la V legislatura, llegaron a aprobarse como leyes 112 proyectos y 14 proposiciones de Grupos del Congreso. El número de proposiciones de ley tomadas en consideración en la XII legislatura es también muy elevado: de Grupos del Congreso, 59 (46 antes de la moción de censura y 13 después); de CCAA, 9 (5 y 4) de 27 presentadas; de reforma de EEAA, 5 ( 4 y 1), todas las presentadas; en el Senado, 14 (6 y 8 ) de 38 presentadas. 
y Economía y Empresa, llegan a fase de comisión 29 textos legislativos en la primera y 13 en la segunda.

En esta fase, se buscan pactos, no necesariamente impulsados por el Grupo del Gobierno, sino por el autor de la iniciativa; a su vez, aquél puede no estar interesado en que avancen proposiciones por él presentadas cuando se hallaba en la oposición. Las ponencias se fortalecen como órganos de negociación que permita alcanzar la aprobación de un texto, prolongándose su labor a lo largo de varias reuniones, frente a la rapidez de la ponencia-rodillo propia de las mayorías absolutas $^{36}$.

Es curioso que, cuando se reactivan las tramitaciones, el número de enmiendas no es muy elevado en comparación con otras legislaturas ${ }^{37}$. Asimismo, se aprecia — como consecuencia de los pactos y de las posiciones distintas que cada grupo ocupa respecto del periodo anterior - la tendencia a que de las ponencias surjan textos transaccionales completos de las iniciativas, que van más allá de la inserción de enmiendas en el texto inicial. Es cierto que las proposiciones, en particular las procedentes de los grupos que por primera vez han accedido a las Cortes Generales, se resentían de cierta falta de calidad técnica, que debía ser suplida en el informe de la ponencia.

\section{Resultado de la actividad legislativa en la legislatura}

En el conjunto de la XII legislatura, el Gobierno presentó 23 proyectos de ley y se aprobaron 39 leyes, 18 procedentes de proyectos (uno de un decreto-ley convalidado) y 21 de proposiciones originarias de otros titulares de la iniciativa legislativa ${ }^{38}$.

Si comparamos este número con otra legislatura de duración similar como la $\mathrm{V}^{39}$ — también de Gobierno minoritario y con idéntico desenlace-, que se

36 Sobre nuestra distinción entre la ponencia-rodillo y la ponencia-consenso, véase P. GARCÍA-EscuDero Márquez, El procedimiento legislativo ordinario en las Cortes Generales, CEC, Madrid, 2006, pp. 340 y ss.

37 Por continuar con el ejemplo de la Comisión de Justicia, de las 23 iniciativas respecto de las que terminó el plazo de enmiendas al articulado ( 5 de ellas cuando ya se había anunciado la próxima disolución de las Cámaras, a 2 de las cuales no se presentaron enmiendas), sólo una superó las 300 enmiendas (protección de datos personales, 369), otra obtuvo 102 (régimen jurídico de los animales), 6 entre 50 y 100, una 32 y 12 menos de 25. De estas iniciativas, 9 se convirtieron en ley y respecto de otras 2 llegó a aprobarse informe de la ponencia.

3815 proposiciones de ley de Grupos parlamentarios del Congreso, 1 proposición de ley orgánica del Senado (LO 1/2017), 2 propuestas de reforma de EEAA (Canarias, LO 1/2018, y Comunidad Valenciana, LO 3/2019) y 3 proposiciones de ley de Comunidades Autónomas (Andalucía, Ley 10/2018; Madrid, LO 2/2018; y CF Navarra, Ley 4/2018).

39 Las elecciones se celebran el 6 de junio de 1993, siendo disueltas las Cámaras por Real Decreto 1/1996, de 8 de enero, que entró en vigor el día 9; en total, dos años y siete meses de legislatura. La XII, de 26 de junio de 2016 a 5 de marzo de 2019, apenas supera los dos años y ocho meses. En ambas, fue la aprobación de las enmiendas de devolución de los presupuestos la que motivó, sin prisas, la disolución anticipada. 
desarrolló entre 1993 y 1996, podemos ver que en ella se presentaron 130 proyectos de ley y 184 proposiciones, aprobándose 112 leyes procedentes de los primeros y 35 de las segundas, en total $147^{40}$, frente a 39 decretos-leyes adoptados por el Gobierno.

Si tomamos la X legislatura, última con un Gobierno efectivo (la XI fue disuelta en aplicación del artículo 99.5 CE, sin candidato investido), en este caso con mayoría absoluta y cuatro años de duración (de 20 de noviembre a 27 de octubre de 2015), vemos que el número de leyes aprobadas en ella es de 168 y el de proyectos presentados de 145. Esta legislatura, por las diferencias expuestas, no podría servir de término de comparación, aunque podemos comprobar que se aprueba un número elevado de leyes, pese a los numerosos decretos leyes dictados como consecuencia de la crisis económica, cuya cifra anual, por otra parte, va decreciendo a lo largo de la legislatura: 29 en 2012, 17 y 17 en 2013 y 2014, 11 en 2015 hasta la disolución, 74 en total (frente a 168 leyes; recordemos que en la XII legislatura, son 65 los decretos-leyes aprobados, frente a 39 leyes).

La comparación con la $\mathrm{V}$ legislatura, breve pero con un sistema cuasibipartidista en el que el Gobierno minoritario se apoyaba en las minorías nacionalistas para gobernar, sí demuestra que, como consecuencia de la fragmentación del Congreso de los Diputados, ni un Gobierno en minoría ni otro supuestamente apoyado en la mayoría que hizo triunfar la moción de censura constructiva, pueden ejercer la actividad ordinaria de iniciativa propia de un régimen parlamentario y, en consecuencia, las Cortes Generales no son capaces de desarrollar una actividad legislativa similar a la de épocas anteriores $(23$ proyectos de ley frente a 130, 39 leyes aprobadas frente a 147; por contra, 65 decretos-leyes frente a 39). Paralización legislativa que a duras penas permite la transposición de directivas o el cumplimiento de reglamentos comunitarios, y - por supuesto- que no refleja la política del Gobierno, contenida en decretos-leyes en la segunda parte de la legislatura.

No sería necesario añadir nada a esta conclusión. No obstante, podemos finalizar de nuevo con preguntas: ¿ha sido favorable para el papel que ocupa el Parlamento en el equilibrio de poderes pasar de un bipartidismo, con sus aspectos negativos, a un pluripartidismo que, en teoría, genera una Cámara más representativa? ¿No es paradójico que, cuanto más débil sea el Gobierno, más poder legislativo ejerza por vía de decreto-ley, eso sí, convalidado por la frágil mayoría que le apoya? Estas serían las preguntas que nos suscita el balance legislativo de una legislatura atípica, partida en dos, y en particular de la segunda parte de la misma, nacida de la moción de censura constructiva.

40 Datos de iniciativas y leyes aprobadas en otras legislaturas, en P. García-Escudero Márquez, $L a$ iniciativa legislativa del Gobierno, CEPC, Madrid, 2000, pp. 34 y ss., «Regeneración del Parlamento, transparencia y participación ciudadana», TRC, n. ${ }^{\circ} 36,2015$, p. 181, y «Un nuevo Parlamento fragmentado para los 40 años de la Constitución», cit., p. 76. 


\section{VICISITUDES PRESUPUESTARIAS}

El dilema de la legislatura que examinamos, ya planteado respecto de la primera parte de la misma, es si se puede gobernar sin presupuestos, que constituyen el instrumento por excelencia de la acción política.

La mayoría inestable no permite aprobar presupuestos en la segunda parte de la legislatura. El conflicto catalán interfiere en los habituales pactos de un Gobierno minoritario con los partidos nacionalistas. Existe un problema añadido: el Senado — de mayoría popular - y su papel equiparado al Congreso en la aprobación del objetivo de estabilidad presupuestaria. El Gobierno, forzado por sus pactos con Unidos Podemos, precisaba modificar dicho objetivo (fijado para el periodo 2018-2020 por acuerdo de ambas Cámaras en julio de 2017) para el año 2019, de forma que le permitiera incrementar el gasto social.

De conformidad con el artículo 15.6 de la L.O. 2/2012, de Estabilidad Presupuestaria y Sostenibilidad Financiera ${ }^{41}$, el acuerdo del Consejo de Ministros en el que se contengan los objetivos de estabilidad presupuestaria y de deuda pública se remitirá a las Cortes Generales. En forma sucesiva y tras el correspondiente debate en Pleno, el Congreso de los Diputados y el Senado se pronunciarán aprobando o rechazando los objetivos propuestos por el Gobierno. Si una de las dos Cámaras — en pie de igualdad en este punto — rechaza los objetivos, el Gobierno, en el plazo máximo de un mes, remitirá un nuevo acuerdo que se someterá al mismo procedimiento.

El Pleno del Congreso rechazó el día 27 de julio de 2018 los objetivos de estabilidad presupuestaria y deuda pública presentados por el Gobierno el 20 de julio, que sólo contaron con el voto a favor de los diputados de los Grupos Socialista y Vasco, absteniéndose UP-ECP-EM, ER y Mixto, siendo el resultado 88 votos a favor, 173 en contra y 86 abstenciones.

A continuación se desarrollan varios intentos de superar la voluntad del Senado que se presumía contraria a un cambio en la senda de déficit. Así, antes de remitir un nuevo Acuerdo:

- los Grupos parlamentarios Socialista, UP-ECP-EM, ER y Mixto (Compromís y PDeCat) presentan el 24 de agosto de 2018 una Proposición de ley de reforma de la L.O. 2/2012, que pretendía modificar el artículo 15.6 al objeto de volver a la redacción contenida en el texto vigente anterior

41 La necesidad de aprobación del objetivo de estabilidad por las dos Cámaras figuraba en el artículo 8.2 de la Ley 18/2001, de 12 de diciembre, General de Estabilidad Presupuestaria. La Ley 15/2006, de 26 de mayo, modificaría este sistema, estableciendo (art. 8.3): «...Si aprobado el objetivo de estabilidad por el Congreso de los Diputados el mismo fuese rechazado por el Senado, el objetivo se someterá a nueva votación del Congreso, aprobándose si éste lo ratifica por mayoría simple», texto que se incorpora al Texto refundido de la Ley General de Estabilidad Presupuestaria, aprobado por Real Decreto Legislativo 2/2007, de 28 de diciembre. La nueva LO de 2012 vuelve al sistema original, igualitario para las dos Cámaras. 
—introducido en la Ley de 2001 por reforma de 2006_- de forma que bastara la mayoría simple del Congreso para superar el rechazo del Senado $^{42}$. La Mesa de la Cámara rechaza su tramitación por procedimiento de urgencia y lectura única. La proposición caducaría con el fin de la legislatura sin que hubiera concluido el plazo de enmiendas al articulado.

— ante el bloqueo de la iniciativa anterior, el Grupo Socialista presenta el 18 de septiembre de 2018 una enmienda a la Proposición de L.O. de reforma de la L.O. 6/1985, de 1 de julio, del Poder Judicial, sobre medidas urgentes en aplicación del Pacto de Estado en materia de violencia de género, que proponía la modificación del artículo 15.6 de la L.O. 2/2012 en el sentido antes expuesto. La enmienda, pese a la doctrina del Tribunal Constitucional iniciada por la sentencia 119/2011 que exige su conexión material con la iniciativa, sería admitida a trámite el 20 de septiembre por la Mesa de la Comisión de Justicia, de mayoría Grupo Socialista-ERC, aunque posteriormente —el 24 de septiembre — inadmitida por la Mesa de la Cámara (mayoría GP-Cs), por exceder de modo manifiesto el objeto de la iniciativa original, constituyendo de facto una iniciativa legislativa distinta, coincidente con la Proposición de Ley a que hemos aludido, que había sido tomada en consideración por el Pleno el 18 de septiembre de 2018.

Cerradas las vías para la reforma de la L.O. 2/2012, un segundo Acuerdo sobre los objetivos de estabilidad enviado por el Gobierno el 7 de diciembre - transcurrido con exceso el plazo de un mes que impone el artículo 15.6 de dicha Ley_-, esta vez aprobado por el Congreso el día 20 por 178 votos a favor y 168 en contra ${ }^{43}$, es rechazado el día 27 por el Senado. Ante la imposibilidad de modificar el objetivo fijado en la senda de déficit, las opciones que se presentaban eran: o bien continuar gobernando con presupuestos prorrogados procedentes de otro Gobierno, que ya había impulsado los del año anterior, o bien presentar unos presupuestos que se ajustaran a la senda aprobada.

El Gobierno optó por lo segundo y, tras las observaciones que en su día le plantearon los organismos europeos sobre el anteproyecto remitido, presenta finalmente el 14 de enero de 2019 un Proyecto de Ley de Presupuestos Generales del Estado para ese año, que resulta criticado por falta de realismo en el cálculo de los ingresos y, por tanto, en el déficit previsto ${ }^{44}$.

42 La exposición de motivos de la proposición hace referencia a que la redacción actual «resulta distorsionadora en tanto responde a un modelo de bicameralismo perfecto que no se corresponde con el que establece nuestra Constitución», con una redacción criticada en su día por el Consejo de Estado, que otorga al Senado una capacidad de bloqueo «que no viene impuesta por ningún precepto constitucional», en un procedimiento para la aprobación de los objetivos de estabilidad presupuestaria y deuda pública distinto al que la propia Constitución establece para la aprobación de los presupuestos.

43 Con el voto a favor de los Grupos Socialista, UP, ER, Vasco y Mixto Compromís y PDeCat.

44 Ver Informe 3/2019 de la Autoridad Independiente de Responsabilidad Fiscal, de los proyectos y líneas fundamentales de presupuestos de las Administraciones Públicas: Proyecto de Presupuestos Generales del Estado 2019, así 
En paralelo, se desarrollan las negociaciones con el Gobierno de Cataluña, o con el partido de gobierno en esa Comunidad Autónoma. Sólo nos interesa aquí su repercusión en el devenir parlamentario: tras hacerse públicos por aquél veintiún puntos de negociación, en los que se incluía la figura de un relator, y la presentación y no retirada de enmiendas a la totalidad de devolución de los Presupuestos por ERC y PDeCat, las negociaciones se rompen. Para más inri, coinciden en el tiempo —22 febrero 2019 — el debate de totalidad de la Ley de Presupuestos y el inicio del proceso ante el Tribunal Supremo contra altos cargos del Gobierno y del Parlamento de Cataluña por los acontecimientos que rodearon el referendum de independencia de 1 de octubre de 2017. El conocido resultado final es el no apoyo a los presupuestos por algunos de los participantes en la moción de censura (ER, En Marea, PdeCat y otros miembros del Grupo Mixto, salvo los diputados de Compromìs, que votan en contra, y el de Nueva Canarias, que se abstiene), de manera que se aprueban las enmiendas a la totalidad de devolución presentadas, votadas conjuntamente, por 191 votos a favor, 158 en contra y una abstención ${ }^{45}$.

A partir de ahí, los acontecimientos se precipitan. La votación desfavorable tiene lugar el miércoles 13 de febrero; el viernes 15, tras un Consejo de Ministros extraordinario, el Presidente del Gobierno anuncia que propondrá al Rey la disolución de las Cámaras para celebrar elecciones el 28 de abril (la fecha considerada más propicia, habida cuenta de las elecciones autonómicas y europeas previstas para el 26 de mayo), lo que significa que quedan todavía dos semanas de actividad parlamentaria, agónicas o de precampaña electoral, según se mire, pero que permitirán concluir la tramitación legislativa de leyes en tramitación en el Senado o pendientes de aprobación definitiva, e incluso la aprobación del informe de una comisión de investigación.

En este apartado, la pregunta la hemos formulado al principio: ¿es posible gobernar sin presupuestos? La respuesta sería sí, como han demostrado algunos períodos de nuestra historia reciente, también en las Comunidades Autónomas, aunque ello dificulte «hacer política». Pero si continuamos analizando las experiencias, vemos que una cosa es la no presentación de presupuestos y otra el rechazo frontal a los presentados mediante la votación favorable a su devolución al Gobierno. Este supuesto ha tenido lugar en el Congreso de los Diputados sólo dos veces, en 1995 y 2019, y en ambas el resultado ha sido la disolución, cierto que sin apresuramiento, buscando la fecha más favorable para las elecciones. En

como comparecencia del Gobernador del Banco de España ante la Comisión de Presupuestos del Congreso de los Diputados el 28 de enero de 2019 (Diario de Sesiones n. ${ }^{\circ}$ 700). Lo que nos trae a la memoria la observación de A. Porras Nadales («La función de gobierno en la Constitución española, cuarenta años despúes», Revista de Derecho Político, n. ${ }^{\circ} 101,2018$, pp. 120-121) sobre la reiterada desconfianza de los Gobiernos hacia instituciones u órganos independientes, considerando que una de las claves de seguridad indirecta del ejecutivo consiste en su riguroso control de la alta administración, a través de la capacidad de nombramiento de sus órganos directivos.

45 Votan a favor de las enmiendas de devolución los diputados del Grupo Popular, En Común Podem (1) y En Marea (1), Cs, ER, Mixto salvo Compromís; en contra, Grupo Socialista, UP-EPC-EM, Grupo Vasco y Compromís; se abstiene el diputado de Nueva Canarias. 
el segundo caso, han concurrido en el desenlace no sólo que el rechazo a los presupuestos fuera muestra de la fragilidad de la mayoría parlamentaria salida de la moción de censura — sobre todo hacia el futuro, a la vista del fracaso de las negociaciones sobre Cataluña-, sino también las supuestas encuestas favorables al partido del Gobierno en las subsiguientes elecciones, a partir del giro en su posición sobre el conflicto catalán.

\section{EL CONTROL AL GOBIERNO, TAMBIÉN POR SUS ALIADOS... Y POR EL SENADO}

Los grupos que actuaron como aliados en la aprobación de la moción de censura, en el fondo rivales electorales, no pueden renunciar a ejercer la función de control de forma parecida al periodo anterior de la legislatura, salvo en algunas votaciones. En consecuencia, examinaremos unas cifras generales sobre el uso de instrumentos de control e indirizzo, en comparación con aquél y con otras legislaturas, y algunos instrumentos que ya habían mostrado una especial relevancia en la primera parte, como las reprobaciones de ministros y las comisiones de investigación.

No hemos de olvidar tampoco, dentro de su escaso margen competencial, que el Senado ejerce la función de control (que no de responsabilidad) en los mismos términos que el Congreso, véase el artículo 66 de la Constitución cuando enumera las funciones de las Cortes Generales. Si en otras ocasiones la mayoría en la Cámara Alta había diferido de la de gobierno, con la aprobación de vetos legislativos (también en los presupuestos) a partir de 2004, en este caso la amplia mayoría del Senado que apoyaba al Gobierno depuesto en la moción reclama un mayor protagonismo en la segunda parte de la legislatura, lo que lleva a algunos incidentes no plenamente resueltos antes de la disolución: constitución de comisiones de investigación y reclamación de la comparecencia del Presidente del Gobierno.

\section{El control al Gobierno en cifras: proposiciones no de ley y preguntas escritas}

En el anterior trabajo sobre el comienzo de la XII legislatura apuntábamos algunos cambios en el uso de los instrumentos ordinarios de control e indirizzo con la nueva composición del Congreso ${ }^{46}$, cambios que se han confirmado. Así, la preferencia de la oposición por las proposiciones no de ley como medio para hacerse visible, por el hecho de implicar una votación de la Cámara aunque carezca de sanción en caso de incumplimiento ${ }^{47}$.

46 P. García-Escudero Márquez, «Un nuevo Parlamento fragmentado para los 40 años de la Constitución», cit., pp. 86 y ss.

47 Apenas si existe en el Reglamento del Senado (art. 178) la norma que establece que en los seis meses siguientes a la aprobación de una moción, el Gobierno o el órgano correspondiente deberán informar sobre el 
Apreciábamos en el primer periodo un crecimiento exponencial en las proposiciones no de ley presentadas y aprobadas, sobre todo en comisión. Tras la moción de censura, la tendencia se mantiene, aunque con menor fuerza. Podemos comparar las cifras con la X legislatura, de cuatro años de duración y Gobierno mayoritario, y con la V legislatura, más parecida a la XII en duración y con un Gobierno en minoría, aunque en un sistema cuasibipartidista:

Proposiciones no de ley ante el Pleno: XII legislatura: presentadas 1.006, aprobadas 85 (73 antes de la moción, 12 después); X legislatura: presentadas 1.315, aprobadas 80; V legislatura: presentadas 261, aprobadas 83.

Proposiciones no de ley en comisión: XII legislatura: presentadas 4.345, aprobadas 1.232 (1083 antes de la moción, 149 después); X legislatura: presentadas 3.921, aprobadas 639; V legislatura: presentadas 692, aprobadas 221.

Comprobamos que, pese a la similitud de las dos últimas legislaturas (de duración muy distinta) en el número de las presentadas y su diferencia abismal con la V, el número de las proposiciones no de ley aprobadas en pleno es muy similar en las tres, aunque la duración de la $\mathrm{X}$ fuera muy superior a la de las otras dos ${ }^{48}$. Ello se debe a que, cuando no existe una mayoría absoluta, cabe adoptar acuerdos en contra del grupo mayoritario y en consecuencia se fomenta el pacto, lo que se ve corroborado por el hecho de que en la XII legislatura, de las 85 aprobadas, 66 lo sean con modificaciones respecto del texto inicial, número igual en la $\mathrm{V}$ legislatura y que desciende a 49 en la $\mathrm{X}$.

No obstante, observamos un descenso considerable en el número de las proposiciones aprobadas en la segunda parte de la legislatura, entre otras cosas por el número reducido de sesiones ordinarias del Pleno del Congreso.

En cuanto a las proposiciones de ley en comisión, las diferencias son abrumadoras, tanto en el número de las presentadas como en las aprobadas en la XII legislatura. Las presentadas superan a las de la X legislatura, de mayor duración, y sextuplican a las de la $\mathrm{V}$, de duración similar.

Las aprobadas en la XII legislatura prácticamente duplican a las de la X y sextuplican (de nuevo) a las de la V. La proporción de las aprobadas con modificaciones respecto al texto inicial, como consecuencia de la aceptación de transacciones, a su vez triplica a las no modificadas: 910 frente a 322 (en la X, 440 frente a 199, el doble; en la V, 187 frente a 34, proporción más parecida a la XII). De nuevo, la ausencia de mayoría propicia los acuerdos, sobre todo en la primera

cumplimiento dado a las mismas, informe que será publicado por la Cámara. Una propuesta de reforma del Grupo Vasco pretende introducir una disposición similar en el Reglamento del Congreso, reforzada con una comparecencia, precisamente por tener conciencia de la falta de efectividad de estos instrumentos. Proposición de reforma del Reglamento del Congreso de los Diputados para el control parlamentario de acuerdos parlamentarios sin fuerza de ley (BOCG Congreso, Serie B, n. ${ }^{\circ} 80-1$, de 30 de enero de 2017), tomada en consideración el 7 de marzo.

48 Téngase en cuenta que el número de proposiciones no de ley tramitadas en el Pleno depende del número de sesiones plenarias y de la limitación de debatir dos en cada una de ellas de carácter ordinario, por lo que nunca podría haber una diferencia tan grande como la que vamos a ver en las comisiones. 
parte de la legislatura, en que el número de proposiciones aprobadas es siete veces superior al de la segunda.

Del análisis efectuado podemos concluir que las proposiciones no de ley en comisión se potencian como forma relativamente sencilla de obtener un pronunciamiento de la Cámara, que rentabiliza también la nueva composición de las Mesas de las comisiones, más proclives a convocar sesiones con este orden del día. Muchas de las medidas aprobadas, dada la falta de vinculatoriedad política, no llegarán a ejecutarse, pero se utilizan como altavoz por las distintas formaciones para dar cumplimiento a su programa electoral en la actividad parlamentaria. También en comisión, esta observación es más aplicable a la primera parte de la legislatura.

Una referencia merecen también las preguntas con respuesta escrita, instrumento mixto de información y control que se ha revelado bastante inadecuado para esta última finalidad. El número de preguntas presentadas ha ido aumentando de tal forma ${ }^{49}$ que ha ahogado su posible utilidad, pues no permite distinguir cuestiones relevantes de otras baladíes, a la vez que fuerza al Gobierno de turno a incrementar los recursos humanos dedicados a su respuesta.

Frente a las 14.886 preguntas para respuesta escrita presentadas en la V legislatura, en la X sumaron 82.299 (en las dos anteriores se habían superado las 100.000). En la XII legislatura se presentan 45.792, número moderado sobre todo en la segunda mitad: 34.786 antes de la moción de censura frente a 11.006 después, cuando la nueva mayoría fragmentada parece comprender la relativa inutilidad de este instrumento de información, dirigido a un Gobierno al que supuestamente apoya.

\section{Las comisiones de investigación}

La XII legislatura se caracteriza, entre otras múltiples notas que hemos ido desgranando, por batir todos los records en cuanto a la creación y constitución de comisiones de investigación. Como apuntamos al estudiar la primera parte de la legislatura, este medio extraordinario de control (previsto por la Constitución como tal en cuanto el artículo 76 dota a tales órganos de facultades exorbitantes) ve facilitada su creación por no disponer el Gobierno de mayoría —o de una mayoría estable - en el Congreso de los Diputados. Dicho de otra manera, pueden crearse contra la voluntad del Gobierno.

La concurrencia de mayoría adversa dio lugar a la creación de cinco comisiones de investigación hasta la moción de censura ${ }^{50}$. Aunque dos de ellas tardaron

49 El número de preguntas para respuesta escrita alcanzó 75.326 en la VII legislatura, 140.322 en la VIII, 104.313 en la IX y «sólo» 82.299 en la X. Incluso en la XI legislatura, de cuatro meses de duración y con un Gobierno en funciones, se presentaron 2.590.

50 Comisiones de investigación constituidas en el primer periodo de sesiones de 2017: de utilización partidista del Ministerio del Interior; sobre la crisis financiera de España y programa de asistencia; sobre la 
unos meses en constituirse, todas llegaron a desarrollar actividad. Dos más fueron creadas por el Pleno tras el cambio de Gobierno pero no llegaron a constituirse (sobre las presuntas responsabilidades políticas derivadas de las irregularidades del proceso de adjudicación, financiación, construcción e indemnización del almacén de gas Castor, el 25 de septiembre de 2018, y relativa a las presuntas irregularidades cometidas por el Instituto de Derecho Público desde su creación en diciembre de 2001 por acuerdo de la Comisión Gestora de la Universidad Rey Juan Carlos el 12 de diciembre del citado año, el 9 de octubre de 2018).

Tanto si tomamos el número de comisiones creadas en la legislatura (7) como el de constituidas (5), podemos comprobar que casi duplica el máximo en las distintas legislaturas anteriores, que es de $3^{51}$, y alcanza la mitad del total de las creadas en cada una de las Cámaras desde la Constituyente (14).

La primera conclusión de estos datos es que la fragmentación parlamentaria facilita la creación de comisiones de investigación; pero después no es tan sencillo alcanzar acuerdos en su seno, de ahí que sólo dos de ellas llegaran a concluir sus trabajos emitiendo dictamen, una en cada periodo de la legislatura: las relativas a la utilización partidista del Ministerio del Interior (aprobación por la Comisión el 20 de julio de 2017 y por el Pleno el 21 de septiembre) y a la crisis financiera (el 29 de noviembre de 2018 y el 28 de febrero de 2019, como último punto del orden del día de la postrera sesión plenaria de la legislatura, in extremis $)^{52}$.

Ya habíamos apuntado la problemática que plantea la práctica de las nuevas comisiones de investigación ${ }^{53}$ : intento de controlar a Gobierno anterior del mismo color que el actual, ámbito temporal de la investigación, delimitación del objeto de la misma (dilucidar responsabilidades políticas o investigar cualquier asunto de interés público, como reza el artículo $76 \mathrm{CE})^{54}$. La reciente sentencia

presunta financiación ilegal del Partido Popular. El 28 de septiembre de 2017 se crea la Comisión sobre el accidente ferroviario ocurrido en Santiago el 24 de julio de 2013, y el 6 de febrero de 2018 la relativa al accidente del vuelo JK 5022 de Spanair. Ambas se constituyen el 18 de abril de 2018.

51 Hay que remontarse a la V legislatura, en un período políticamente complicado, para la creación de tres comisiones de investigación (sobre fondos asignados a la Dirección de la Guardia Civil, sobre la situación del patrimonio de D. Mariano Rubio y sobre el proceso de privatización de la empresa pública Intelhorce). Antes hubo tres también en la II, sobre Rumasa, catástrofes aéreas en Barajas y financiación de partidos políticos. Se crearon dos en la VI, IV y I legislaturas, y 1 en las legislaturas VIII, VII y III. Las últimas Comisiones de investigación en el Congreso fueron en la VIII legislatura, sobre el 11 de marzo de 2004, y en la VII, sobre Gescartera. En el Senado, se constituyeron tres en la I, 6 en la II, 2 en la III y la IV, siendo la última la abortada en la V legislatura sobre la creación y actuación de los GAL. La única Comisión Mixta de Investigación constituida, sobre el síndrome tóxico, se crea en la II legislatura. En total, 14 en cada Cámara y 1 mixta Congreso-Senado en 11 legislaturas.

52 Este dictamen fue aprobado por 308 diputados a favor y 32 en contra (los de Ciudadanos), entre otras razones porque refuta la teoría de que el problema de las Cajas era su politización, inclinando las críticas hacia la actuación de los organismos reguladores, en particular el Banco de España.

53 P. García-Escudero Márquez, «Un nuevo Parlamento fragmentado para los 40 años de la Constitución», cit., pp. 88 y ss.

54 Algunos temas, de dudosa admisibilidad como objeto de comisiones de investigación, han sido recurrentes: dos sobre presuntas ilegalidades cometidas por el Monarca emérito - la segunda sobre el ex Jefe del Estado especificando desde que dejó de serlo_ presentadas por diputados de UP-EPC-EM — la segunda 
del Tribunal Constitucional 133/2018, de 13 de diciembre, algo clarifica en cuanto a las calificaciones que pueden verterse en las conclusiones sobre responsabilidades penales, que desbordan la investigación parlamentaria ${ }^{55}$. No obstante, es posible que los nuevos Parlamentos fragmentados, tanto autonómicos como estatal, den origen a nuevos pronunciamientos.

Destacábamos en su momento algunas otras cuestiones que se han suscitado con los nuevos tiempos: la coincidencia de comisiones en las Cortes Generales y en los Parlamentos autonómicos sobre temas similares, que plantean dudas sobre la competencia respectiva; incidencias en el caso de coexistencia de investigaciones parlamentarias y judiciales, etc. Alcanzado el final de la legislatura, habrá que preguntarse si la actividad desarrollada y no culminada por este número inhabitual de comisiones de investigación, cuyos debates en ocasiones han alcanzado repercusión pública más por la forma que por el fondo, ha de considerarse positiva o no para la institución parlamentaria y para la función de control que el propio instrumento extraordinario tiene constitucionalmente atribuida.

Se olvida a veces que para el estudio de asuntos concretos sobre los que se desea alcanzar conclusiones que sirvan para prevenir supuestos similares, como también para la mejora de la normativa reguladora, existe el instrumento de las comisiones especiales o las ponencias y subcomisiones. De la posibilidad de obtener mejores resultados llegando a acuerdos da cuenta el que, de 13 ponencias de estudio o subcomisiones constituidas en el Congreso de los Diputados en la XII legislatura, 7 aprobaran informe, alguno en materia tan política como el régimen y la financiación de los partidos políticos, la imparcialidad e independencia de autoridades independientes y la protección de los denunciantes de los casos de corrupción ${ }^{56}$.

por este grupo con ER - fueron inadmitidas a trámite en el Congreso el 4 de septiembre y el 23 de octubre de 2018; en el Parlamento de Navarra, una propuesta de creación de comisión de investigación sobre la repercusión de en los fondos públicos navarros de la actuación de aquél fue asimismo inadmitida por la Mesa el 17 de diciembre de 2018; el Parlamento de Cataluña aprueba el 7 de marzo de 2019 la creación de una comisión de investigación sobre la monarquía por 71 votos a favor y 56 en contra, acto que el Gobierno de la Nación acuerda impugnar ante el Tribunal Constitucional al amparo del Tíbulo V LOTC el 15 de marzo (admisión a trámite 26 marzo, BOE 29 marzo; STC 2 octubre 2019, cerrado este trabajo).

55 En recurso de amparo planteado por el Director de recursos humanos de la empresa pública Ferrocarriles de la Generalitat Valenciana (FGV) contra las conclusiones del dictamen de la Comisión de investigación de las Cortes Valencianas sobre el accidente de la línea 1 de Metro Valencia ocurrido el 3 de julio de 2006, en cuanto en ellas se declara al recurrente responsable, entre otras personas, del accidente, el fallo considera lesionado su derecho al honor y declara la nulidad de la conclusión referida al demandante. El Alto Tribunal recuerda la naturaleza no jurisdiccional de la actividad parlamentaria investigadora y que las Cámaras no son titulares del ius puniendi jurisdiccional ni de la potestad administrativa sancionadora. En consecuencia, «a las Cámaras, en el ejercicio de su actividad investigadora, ni les corresponde efectuar una calificación jurídica de los hechos investigados, ni llevar a cabo imputaciones o determinaciones personales sobre la autoría de comportamientos ilícitos» (FJ 8).

56 Aprobaron también su informe las subcomisiones o ponencias en materia de política de aguas en coherencia con los retos del cambio climático, ciberseguridad en España, menores sin alcohol, régimen profesional de militares de tropa y marinería, estatuto del artista y pacto de Estado en materia de violencia de género. No concluyeron sus trabajos las relativas a actualización de cooperación internacional para el desarrollo, reforma electoral, reforma del RETA, estrategia nacional de Justicia, pacto de Estado social y político por la educación y consecuencias del BREXIT. 


\section{La reprobación de ministros}

La primera parte de la legislatura se había distinguido por la proliferación en el Congreso de los Diputados de un instrumento de control no previsto en la Constitución, hasta el punto de que se convierte en cuasiordinario: se presentan hasta la moción de censura 13 propuestas de reprobación contra miembros del Gobierno u otras altas autoridades, 8 de las cuales son aprobadas por el Pleno (Ministra de Sanidad, Servicios Sociales e Igualdad, 29 mayo 2018; Asuntos Exteriores y Cooperación, 7 noviembre 2017; Interior y Asuntos Exteriores y Cooperación, 24 octubre 2017; Hacienda y Función Pública, 29 de junio de 2017, Secretario de Estado de Seguridad, 20 junio 2017; Ministro de Justicia, 16 mayo 2017; del Interior, 18 octubre 2016) ${ }^{57}$.

Sin perjuicio de que quepa destacar la conversión en habitual de un instrumento que choca con la declaración de responsabilidad solidaria del Gobierno (108 CE) y su nulo efecto jurídico o de exigencia de responsabilidad política mediante la dimisión, el resultado es coherente con el hecho de que, hasta la moción de censura, el Ejecutivo se enfrentaba a una mayoría adversa en la Cámara.

Lo llamativo es que, con el segundo Gobierno de la legislatura, se aprueba la reprobación de la Ministra de Justicia por la mayoría de la Cámara. Presentada por el Grupo Popular, para su triunfo era necesaria al menos la abstención, que se produce, de alguno de los socios en la censura, en concreto de ER y de los diputados de EH Bildu del Grupo Mixto ${ }^{58}$.

Otras dos reprobaciones son solicitadas en este periodo por Unidos Podemos (Ministra de Industria, Comercio y Turismo, 15 de enero de 2019) y PDeCat (Ministro de Asuntos Exteriores, Unión Europea y Cooperación, 28 noviembre 2018), asimismo participantes en la censura que supuso el cambio de gobierno. Es cierto que estas iniciativas se producen al final de la legislatura, cuando ya se habían puesto de manifiesto las fisuras en la mayoría multicolor que apoyó la moción, pero merecen una mención, como una muestra más de su fragilidad.

\section{El Senado contra el Gobierno}

Ya habíamos señalado, respecto de la primera parte de la legislatura, cómo el Grupo Popular, sobre la financiación de cuyo partido se constituye una comisión de investigación contra su voluntad en el Congreso, crea en el Senado otra cuyo

57 Además de otras autoridades, como el Fiscal General del Estado, el Fiscal Jefe de la fiscalía Especial contra la Corrupción y la Criminalidad organizada, cargos nombrados por el Gobierno pero respecto de los que se propugna la independencia.

58 El resultado de la votación es de 167 votos a favor (GP, Cs, Mixto UPN y Foro, 1 de UP), 162 en contra (1 GP, GS, UP-ECP-EM, Grupo Vasco, Grupo Mixto salvo los anteriores y EH BIldu), 11 abstenciones (ER, Mx EH Bildu). 
objeto se extiende a la financiación de todos los partidos políticos ${ }^{59}$. Esta Comisión se mantiene activa toda la legislatura (aunque no participaron en su trabajo los restantes Grupos), celebrando 36 sesiones y llamando a comparecer a numerosos responsables de partidos, si bien no llega a emitir informe. En todo caso, la repercusión mediática de la actividad del Senado es siempre menor que la del Congreso.

Pero nos interesa centrarnos en dos cuestiones que se plantean en la segunda parte de la legislatura: la creación de una comisión de investigación sobre la tesis doctoral del Presidente del Gobierno investido en la moción de censura y los intentos de que comparezca en Pleno.

El 11 de octubre de 2018, el portavoz del Grupo Popular en el Senado y 24 senadores más (veinticinco que no pertenezcan al mismo Grupo parlamentario, exige el art. 59.1 del Reglamento) solicitan la creación de una Comisión de Investigación sobre la elaboración y autoría de la tesis doctoral firmada y leída por el Presidente del Gobierno, D. Pedro Sánchez Pérez Castejón ${ }^{60}$ (el título con el que se crea era más largo), que es aprobada por el Pleno de la Cámara el 7 de noviembre, como contrapartida a la creada en el Congreso el 9 de octubre sobre las irregularidades cometidas por el Instituto de Derecho Parlamentario de la Universidad Rey Juan Carlos. Constituida el 4 de diciembre de 2018, tras el aplazamiento de una sesión prevista para el 9 de enero, en la sesión celebrada el 1 de marzo de 2019 — en puertas de la disolución de las Cámaras que se acordaría el día 4aprueba el plan de trabajo propuesto por el Grupo Popular, con discursos que son más de conclusiones de sabor preelectoral. La portavoz del Grupo Popular afirma en su intervención que se les habían pedido dos meses de espera (para preparar el plan de trabajo) y que el final coincide con la convocatoria de elecciones. En cualquier caso, una vez creada la comisión, no parece que se haya buscado el confrontamiento directo haciendo valer la mayoría hasta sus últimas consecuencias (el Presidente del Gobierno estaría obligado a comparecer ante la Comisión si así se acordara, por aplicación del art. $76 \mathrm{CE}$, con consecuencias penales en supuesto de incumplimiento de la obligación).

El segundo asunto a examinar, muestra de la mayoría en el Senado opuesta al Gobierno, afecta a la comparecencia en Pleno del Presidente del Gobierno. El Presidente había acudido el 18 de diciembre de 2018 ante el Pleno del Senado para informar conjuntamente sobre las líneas generales de actuación del Gobierno y sobre la crisis migratoria que sufre España. Al parecer, esta comparecencia se insertaba en un acuerdo político de que el Presidente acudiera al Pleno cada pocos meses.

59 Comisión de Investigación sobre la financiación de los partidos políticos y el estudio de las medidas que permitan avanzar en el compromiso de transparencia adoptado y que, a su vez, impidan supuestos de financiación ilegal en el futuro. Creada por el Pleno el 5 de abril de 2017 y constituida el 6 de junio de 2017 (una vez que la del Congreso echó a andar).

60 Previamente se había solicitado su comparecencia en Pleno "para informar sobre las sospechas de plagio en su tesis doctoral y las dudas sobre su autoría», solicitud que fue retirada. 
A petición de la mayoría absoluta de los senadores (142 senadores del Grupo Popular), como establecen los artículos 73.2 CE y 70 RS, el Presidente del Senado convoca sesión plenaria extraordinaria para el día 24 de enero de 2019, teniendo como único punto del orden del día la comparecencia del Presidente del Gobierno para informar sobre las demandas planteadas en el documento que el Presidente de la Generalitat de Cataluña le entregó en la reunión bilateral celebrada el día 20 de diciembre de 2018, así como sobre los acuerdos alcanzados y las concesiones realizadas. El Presidente del Gobierno no comparece en la sesión y, por acuerdo de la Junta de Portavoces, tiene lugar un turno de portavoces —en tono encendidoabandonando el hemiciclo al comienzo los senadores de ER y, cuando va a intervenir el portavoz del Grupo Popular, asimismo los miembros del Grupo Socialista, del PDeCAT y del Grupo Parlamentario Nacionalista Partit Demòcrata — Agrupación Herreña Independiente-Coalición Canaria, y de Coalición Compromís y EH Bildu del Grupo Parlamentario Mixto, según el Diario de Sesiones.

Aunque el debate en los medios de comunicación parecía versar sobre si el Senado posee la facultad de solicitar la comparecencia del Presidente del Gobierno $^{61}$, la Constitución no distingue entre las Cámaras cuando declara en el artículo 110 que éstas y sus comisiones podrán reclamar la presencia de los miembros del Gobierno. Al final, las disensiones en sede parlamentaria se recondujeron al ámbito de la cortesía, alegando que no se había concertado la fecha y que el Presidente se encontraba fuera de España ${ }^{62}$. Pero la realidad es que, una vez más, el Senado se ve postergado porque tampoco lleva hasta las últimas consecuencias - las que podrían derivarse de la incomparecencia- el ejercicio de su mayoría. Por el contrario, el Presidente compareció el 27 de febrero ante el Pleno del Congreso para responder a otros temas, a solicitud de diputados del Grupo Popular que sumaban más de la quinta parte de los miembros de la Cámara, como exige el artículo 203.1 RC, previo acuerdo de la Mesa y de la Junta de Portavoces.

\section{LA FUNCIÓN DE NOMBRAMIENTO}

La nueva composición fragmentada del Congreso de los Diputados afecta profundamente a la función de integración de otros órganos que la Constitución

61 Sobre la base de que el art. 66 RS sólo prevé las comparecencias informativas en comisión, sin que exista un precepto similar al 203 RC, según el cual «los miembros del Gobierno, a petición propia, o por acuerdo de la Mesa de la Cámara y de la Junta de Portavoces, comparecerán ante el Pleno o cualquiera de las Comisiones para informar sobre un asunto determinado. La iniciativa para la adopción de tales acuerdos corresponderá a dos Grupos Parlamentarios o a la quinta parte de los miembros de la Cámara o de la Comisión, según los casos».

62 Véase acta de la reunión de la Mesa del Senado de 12 de febrero de 2019 en la página web de la Cámara (consultado 14 marzo 2019), donde también se encuentra el Informe elaborado por la Secretaría General del Senado sobre la competencia del Senado para solicitar la comparecencia del Presidente del Gobierno, con indicación de precedentes. 
atribuye a las Cortes Generales. Augurábamos que, aunque los Grupos Socialista y Popular superaran conjuntamente los tres quintos exigidos por la Constitución para el nombramiento de miembros de órganos constitucionales y de relevancia constitucional, no sería defendible en la nueva época aplicar automáticamente el sistema de cuotas vigente durante el bipartidismo, aun con cesión de puestos a otros partidos.

Aparte de la permanencia en funciones del Defensor Adjunto del Pueblo desde julio de 2017, dos supuestos — ambos fracasados — han puesto de relieve, de una parte, que los antiguos modos no son ya operativos y, de otra, que los experimentos osados tampoco salen bien. Nos referimos a la frustrada renovación de miembros del Consejo General del Poder Judicial y de Presidente y miembros del Consejo de Administración de la Corporación RTVE, que analizaremos en orden inverso. Un incidente final en relación con el nombramiento de miembros del Consejo de Seguridad Nuclear merecerá asimismo un comentario.

\section{Consejo de Administración de la Corporación RTVE}

La Ley 5/2017, de 29 de septiembre, por la que se modifica la Ley 17/2006, de 5 de junio, de la radio y la televisión de titularidad estatal, para recuperar la independencia de la Corporación RTVE y el pluralismo en la elección parlamentaria de sus órganos (hasta aquí el título de la Ley), tramitada por el procedimiento de lectura única - lo que explicará alguno de sus problemas de aprobación ${ }^{63}$ y aplicación posterior-, tiene por objeto dejar sin efecto la reforma introducida por el Real Decreto-ley 15/2012, de 20 de abril, de modificación del régimen de administración de la Corporación RTVE, previsto en la Ley 17/2006, de 5 de junio, requiriendo de nuevo la mayoría de dos tercios en cada una de las Cámaras para el nombramiento de los miembros del Consejo de Administración que le corresponde elegir (6 Congreso y 4 Senado, aumentando en uno los nombrados por el Congreso), en lugar de la posible aprobación por mayoría absoluta de cada Cámara transcurridas veinticuatro horas desde la primera votación que establecía el Decreto-ley ${ }^{64}$.

Aprobada la Ley 15/2017, resurge inmediatamente la falta de acuerdo, que impide la aprobación, en el plazo de tres meses establecido por la Ley, de la

63 La aplicación del procedimiento de lectura única a un texto sin acuerdo y complejo provocó que en la aprobación por el Pleno del Congreso el 22 de junio de 2017 se produjeran varios empates y la incorporación de enmiendas incongruentes entre sí, como las relativas al número de miembros del Consejo de Administración de RTVE (Diario de Sesiones n. ${ }^{\circ}$ 64, de 22 de junio de 2017).

64 Para la primera elección posterior a la Ley, su disposición transitoria primera dispone que en segunda votación efectuada en plazo no inferior a quince días, basta la mayoría absoluta, siempre que la candidatura haya sido propuesta por, al menos, la mitad de los grupos parlamentarios de la Cámara que corresponda. 
normativa necesaria para poner en marcha la selección de candidatos por las Cortes Generales, previo concurso público con la participación de un Comité de expertos, gran novedad que pretendía sustituir al sistema anterior de cuotas. El primer problema se suscita respecto a la normativa vigente a aplicar, que la Ley señala como supletoria para el caso de no acuerdo, teniendo en cuenta además que algunos preceptos del Real Decreto-Ley de 2012 habían sido declarados inconstitucionales.

Y aquí se produce la incidencia más reseñable del proceso. En estos momentos iniciales, cuando no se llega a la aprobación en sede parlamentaria de las normas, el Gobierno salido de la moción de censura aprueba su primer decreto-ley: Real Decreto-ley 4/2018, de 22 de junio, por el que se concreta, con carácter urgente, el régimen jurídico aplicable a la designación del Consejo de Administración de la Corporación RTVE y de su Presidente, que sería convalidado el 4 de julio por el Pleno del Congreso de los Diputados por 179 votos a favor y 165 en contra.

El preámbulo del Decreto-ley justifica su aprobación en «asegurar el fin de esta situación de parálisis que impide llevar a cabo objetivos que fueron fijados por las propias Cámaras al aprobar la ley en 2017» y en la circunstancia de que el entonces Consejo de Administración de RTVE había finalizado su mandato ${ }^{65}$ : «es necesario corregir con urgencia la anomalía ${ }^{66}$ que supone que todos los consejeros hayan agotado su mandato y, sobre todo, evitar la parálisis que podría producirse en el funcionamiento ordinario del Consejo de Administración por la ausencia de un Presidente con plenas capacidades».

«Para desbloquear la situación institucional en la que se encuentra actualmente la Corporación RTVE», el Decreto-Ley regula «de forma urgente y provisional la elección de los miembros del Consejo de Administración hasta la efectiva aplicación de la Ley de 2017», en la forma siguiente:

- las Cámaras habrían de elegir en el plazo de quince días naturales desde la entrada en vigor del decreto-ley a los diez consejeros previstos en la Ley 17/2006; una vez elegidos, en el mismo plazo de quince días naturales el Congreso de los Diputados designaría al consejero que desempeñara el cargo de Presidente de la Corporación y del Consejo, en el caso de que hubiera finalizado su mandato. La mayoría exigida en ambos casos sería de dos tercios en primera votación y absoluta en la segunda, tras cuarenta y ocho horas,

65 «Aunque existe una previsión en el artículo 12 de la Ley 17/2006 por la que los consejeros salientes pueden continuar en funciones hasta el nombramiento de los nuevos, no existe una previsión similar para el caso del Presidente de la Corporación, con los problemas de gestión que tal circunstancia puede suponer».

66 La situación de expiración del mandato de cargos electos por las Cámaras no ha sido precisamente anómala en nuestro periodo constitucional, si usamos el término como contrapuesto a usual, lo que ha originado algunas modificaciones legislativas para establecer la prórroga de los cargos cesantes hasta que se produzca la nueva elección. 
pero con una propuesta de candidatura que proviniera de, al menos, la mitad de los grupos parlamentarios de la Cámara que corresponda.

- transcurrido el plazo de quince días sin que el Senado hubiera elegido sus consejeros, el Congreso podría («excepcionalmente») y en el plazo de diez días naturales adicionales, proceder a la elección de estos, respetando las candidaturas que, en su caso, ya se hubieran presentado en el Senado ${ }^{67}$. El mandato de estos consejeros y del presidente, que sería renovable, finalizaría cuando fueran nombrados los elegidos conforme al procedimiento previsto en la Ley 5/2017.

- si en los plazos señalados las dos Cámaras, o el Congreso, no hubieran procedido a la elección de los consejeros, el Gobierno propondría el nombramiento de un administrador provisional único para la Corporación al Congreso de los Diputados, cuya elección requeriría la mayoría de dos tercios en primera votación y absoluta en segunda, tras cuarenta y ocho horas. Este «administrador provisional único», hasta que se produjeran los nombramientos de consejeros de acuerdo con la Ley $5 / 2007^{68}$, ostentaría las competencias atribuidas por la Ley 17/2006, reguladora de la radio y televisión de titularidad estatal, al Consejo de Administración y al Presidente de la Corporación.

Huelga decir que, en los exiguos plazos establecidos por el Decreto-ley, no se nombraron consejeros por las Cámaras, al fracasar la elección en el Senado y no ser elegidos por el Congreso los candidatos de la otra Cámara ${ }^{69}$. El Gobierno acuerda el 20 de julio de 2018 proponer al Congreso el nombramiento de admi-

67 Vemos aquí, esta vez aprobado, un nuevo supuesto de sortear la voluntad — calificable de bloqueo- de una Cámara con mayoría adversa al Grupo del Gobierno, que resulta en una desigualdad que la Constitución no establece para la función de nombramiento (frente al argumento utilizado en los intentos expuestos en materia de estabilidad presupuestaria).

68 La disposición transitoria segunda de la Ley es asimismo modificada por el Decreto-ley, de manera que se regula la composición y designación del Comité de Expertos y la audiencia y elección posterior de los candidatos.

69 En sesión extraordinaria — como todas las siguientes_ celebrada el 4 de julio de 2018, el Pleno del Congreso de los Diputados, en segunda votación y por mayoría absoluta (177 votos a favor), elige a los 6 miembros del Consejo de Administración que le corresponden (BOCG n. ${ }^{\circ}$ 387, 10 julio 2018), que no habían obtenido mayoría de dos tercios el día 2 de julio (véanse en el Diario de Sesiones las protestas sobre el procedimiento formuladas por distintos portavoces); en el Senado, el 3 y el 5 de julio ninguno de los candidatos propuestos que habían comparecido ante la Comisión de nombramientos alcanza la mayoría requerida en primera ni en segunda votación (BOCG n. ${ }^{\circ}$ 260, 15 de julio). Los días 10 y 16 de julio se realiza la votación en el Congreso sobre los candidatos propuestos y no elegidos en el Senado, no obteniendo ninguno la mayoría suficiente y quedando por tanto sin efecto la elección de candidatos realizada por el Congreso el 4 de julio (BOCG n. ${ }^{\circ}$ 395, 20 de julio). La última votación, con 305 votos emitidos (los diputados del Grupo Ciudadanos abandonaron el hemiciclo antes de comenzar aquélla, según recoge el Diario de Sesiones), arroja el resultado de 175 votos a favor de los 4 candidatos propuestos por al menos la mitad de los grupos parlamentarios del Senado, a uno de la mayoría absoluta requerida, 2 votos en blanco y 128 nulos por no contener el nombre de los candidatos propuestos hasta un máximo de cuatro. La prensa destaca dos ausencias de PDeCat y dos votos erróneos (El Mundo, 17 julio 2018), que la portavoz socialista achacó a un fallo humano, descartando que se hubiera hecho de forma intencionada ( $A B C$, misma fecha). 
nistradora provisional única, que es elegida por el Pleno el 27 de julio en segunda votación (no se había alcanzado mayoría de dos tercios el día 25) por mayoría absoluta $^{70}$ (BOCG n. ${ }^{\circ}$ 401, 30 julio).

Entretanto, las normas para la renovación de los miembros del Consejo de Administración son aprobadas el 10 de julio de 2018 por Resolución de las Mesas del Congreso de los Diputados y del Senado, en reunión conjunta (BOCG Cortes Generales n. ${ }^{\circ} 214$, de 13 de julio). La Resolución regula la convocatoria y requisitos, la constitución del Comité de Expertos — designado a propuesta de los grupos parlamentarios por la Comisión Mixta de control parlamentario de la Corporación RTVE_ - que evalúe las solicitudes presentadas, la comparecencia de los candidatos seleccionados (los acuerdos son recurribles ante la Mesa de la Comisión Mixta, y a su vez estos ante las Mesas de ambas Cámaras en reunión conjunta) ante la Comisión Consultiva de Nombramientos en el Congreso, la designación por el Pleno, la comparecencia de los no elegidos ante la Comisión de Nombramientos del Senado y su votación en Pleno, así como en su caso una segunda elección complementaria previa apertura de nuevo plazo de solicitudes. De acuerdo con lo dispuesto en la Ley, el Congreso de los Diputados había de elegir de entre los Consejeros electos al Presidente de la Corporación y del Consejo.

A partir de ahí, el procedimiento sigue avanzando, convocándose el concurso por Resolución de los Presidentes de las Cámaras de 17 de julio, y siendo designados los miembros del Comité de Expertos por la Comisión Mixta el 27 de julio. El 30 de julio se constituye el Comité de Expertos, el 10 de agosto la Mesa de la Comisión Mixta aprueba la lista provisional de candidatos admitidos (17) y de numerosos excluidos y el 6 de septiembre la lista definitiva (92 admitidos, más otros 3 que añadiría en recurso la Mesa de la Comisión Mixta, contra lo que formulan queja los miembros del Comité de Expertos). En la misma fecha, el Comité de Expertos aprueba el baremo para la valoración de méritos de los candidatos (BOCG n. ${ }^{\circ}$ 273, de 17 de agosto), en el que se establece que serán considerados idóneos los 20 candidatos que obtengan las calificaciones más altas, siempre que superen los 65 puntos. El informe de evaluación de idoneidad de los candidatos se aprueba el 10 de diciembre (BOCG n. ${ }^{\circ}$ 256, 18 de diciembre), abriéndose con la publicación un plazo de quince días naturales para la presentación de recursos ante la Mesa de la Comisión Mixta, que no resuelve los muchos presentados antes de la disolución de las Cámaras. La Mesa de la Cámara trasladará el asunto a la XIII legislatura.

Hasta aquí el tortuoso y a la vez acelerado procedimiento, después del parón inicial previo a la aprobación de las normas. El experimento de elección parlamentaria mediante concurso público e intervención de un comité de expertos, que preconizaban las nuevas formaciones políticas, no ha finalizado con éxito. Además de concluir en la necesidad de que los cambios normativos se aprueben con mayor sosiego y previsión de los problemas que se puedan plantear, el

70180 votos a favor, 1 en blanco y 131 votos nulos. 
conjunto del proceso suscita preguntas o reflexiones que, en el fondo, son similares a las formuladas en apartados anteriores:

Si el resultado final es que se haya situado al frente de la Corporación RTVE una única administradora - que concentra las funciones del Presidente y de un Consejo hasta ahora plural—, propuesta por el Gobierno, aun elegida por mayoría absoluta del Congreso de los Diputados-, ¿no crece el poder del Gobierno minoritario frente al Parlamento fragmentado?

¿Cabrá utilizar el decreto-ley para superar bloqueos parlamentarios — con candidatos propuestos por el Gobierno- en cualquier otro nombramiento (no regulado por ley orgánica), frente a la tradicional prorrogatio a que nos había habituado el sistema de cuotas? ¿No supone de nuevo inclinar la balanza hacia el ejecutivo — abstracción hecha de la existencia o no de presupuesto habilitante- en este y en otros futuribles casos, en competencias propias de las Cámaras, en concreto la función de nombramiento?

¿Es legítimo que el Gobierno fuerce la voluntad —o la falta de voluntadde las Cámaras debida a la composición salida de las urnas, que no llegan a realizar los nombramientos en plazo ${ }^{71}$ ¿Permiten las diferencias de composición entre las dos Cámaras acudir, no ya a la ley, sino al decreto-ley para disminuir las facultades del Senado cuando la ley lo sitúa en plano de igualdad con el Congreso, sobre todo en materia de nombramientos, en los que las previsiones constitucionales son de paridad entre las Cámaras?

En todo caso, debe destacarse de nuevo, como última reflexión, que el resultado final — querido o no— ha sido la eventual sustitución de un Presidente y un Consejo de Administración plural en funciones por una única administradora al frente de la radio y la televisión pública; supuestamente provisional (para un periodo breve, que se presumía en torno a tres meses), pero cuyo mandato se ha extendido siete meses hasta la disolución de las Cámaras y más allá — cuando no existe control parlamentario (previsto en el artículo 20.3 de la Constitución) por la Comisión competente-, a

71 En un supuesto similar, la no elección de miembros del Instituto Federal Electoral, en la sentencia SUP-JDC-12639/2011 la Sala Superior del Tribunal Federal Electoral de México resuelve requerir «a la Sexagésima Primera Legislatura de la Cámara de Diputados, proceda a celebrar los actos propios y necesarios tendentes a la designación de los consejeros electorales del Consejo General del Instituto Federal Electoral en los términos precisados en el último considerando» de la ejecutoria, informando a la Sala Superior respecto al cumplimiento que se diera a la misma. La Sentencia se dictó el 30 de noviembre de 2011 y el 15 de diciembre del mismo año la Cámara de diputados designó a los ciudadanos que integrarían las vacantes de Consejeros electorales, esto es, dio cumplimiento a aquélla. Un comentario a esta sentencia y las dudas que planteaba, puede verse en mi Ponencia sobre «La integración del IFE. Problemática de la integración de órganos por el Parlamento». Seminario «Proceso electoral federal 2012», organizado por el Tribunal electoral del Poder Judicial de la Federación (México). México DF, 11-12 de octubre de 2012. En P. García-Escudero MárQUEZ, «La problemática de la integración de órganos por el Parlamento» (Asamblea, n. ${ }^{\circ}$ 27, 2012, pp. 11-23) ya mantenía que ningún órgano, ni siquiera el Tribunal Constitucional, puede sustituir al Parlamento en la inclusión de un asunto en su orden del día, o en caso de que aborten los intentos de alcanzar un consenso entre los grupos parlamentarios o de que en la propia votación no se alcance la mayoría requerida ¿Qué medios tendría a su disposición el órgano controlador para ejecutar su sentencia? ¿Podría acaso suplir la voluntad de la Cámara expresada mediante votación por una determinada mayoría? 
lo largo de dos procesos que concentran elecciones generales, autonómicas de 14 Comunidades Autónomas, municipales y europeas. Sin comentarios.

\section{Renovación del Consejo General del Poder Judicial}

El otro supuesto relevante de integración de órganos por las Cortes Generales que se desarrolla durante la segunda parte de la XII legislatura y que debe ser entendido a la luz de la nueva composición del Congreso, es el relativo a la renovación del Consejo General del Poder Judicial. En este caso veremos cómo los antiguos hábitos propios del bipartidismo no resultan tampoco plenamente operativos en el nuevo escenario.

El 3 de agosto de 2018, se recibe comunicación del Presidente del Consejo de la próxima expiración del mandato, informando del inicio del proceso de renovación de los vocales correspondientes al turno judicial ${ }^{72}$ mediante la apertura del plazo de presentación de candidaturas por jueces y asociaciones.

Paralelamente, en la tramitación en el Congreso de los Diputados de la Proposición de L.O. de reforma de la L.O. 6/1985, de 1 de julio, del Poder Judicial (originariamente en materia de permisos y licencias), se debate una nueva forma de designación de los vocales judiciales, que también se trató de consensuar en la fallida Subcomisión sobre estudio y definición de una estrategia nacional de Justicia (cuyo mandato expiró el 1 de marzo de 2018 sin emitir informe). El texto de la Proposición se aprueba en el Congreso el 30 de octubre de 2018 sin acuerdo en este punto (se modifican cuestiones importantes de funcionamiento del CGPJ, como las relativas a las funciones de Pleno y Comisión Permanente o a nombramientos). En el Senado, el 12 de diciembre se introducen enmiendas — con votaciones confusas en el Pleno- para volver al sistema de designación de vocales judiciales anterior a la LOPJ, esto es, elección directa por jueces y magistrados, que serían rechazadas por el Pleno del Congreso el 20 de diciembre. El final convulso de la tramitación se explica por los incidentes del proceso de designación de vocales juristas que se exponen a continuación, con ruptura del pacto PP-PSOE.

Las candidaturas para el turno judicial definitivamente aprobadas se publican en el BOCG el 15 de octubre de 2018, a la vez que se abre un plazo de

72 De conformidad con el art. 122.3 CE y 566 LOPJ, el CGPJ estará integrado por el Presidente del Tribunal Supremo, que lo presidirá, y por veinte vocales, de los cuales doce serán jueces o magistrados en servicio activo en la carrera judicial y ocho juristas de reconocida competencia. No entraremos en las distintas modificaciones normativas sobre la forma de nombramiento de los vocales judiciales desde la aprobación de la Constitución, simplemente recordar que el art. 568 LOPJ establece que el Presidente del TS y del CGPJ, cuatro meses antes de la expiración del plazo de cinco años desde la constitución del anterior Consejo, dispondrá: a) la remisión a los Presidentes de Congreso y Senado de los datos del escalafón y del Registro de Asociaciones judiciales y b) la apertura del plazo de presentación de candidaturas para la designación de los vocales correspondientes al turno judicial. Los arts. 572 y siguientes regulan la presentación de candidaturas, con el aval de una asociación judicial o de 25 miembros de la carrera judicial, y la proclamación de candidaturas por una Junta electoral, así como los recursos posibles. 
presentación de candidaturas para los cuatro vocales del turno de juristas que corresponde elegir al Congreso, de acuerdo con el artículo 122.3 CE. Este plazo se amplía varias veces y concluye finalmente el 12 de noviembre de $2018^{73}$. Ese día, los Grupos Socialista y Popular presentan una candidatura conjunta (4 candidatos y 3 suplentes). Por su parte, UP-ECP-EM (Cs ya había anunciado que se abstenía de participar en cualquier pacto) presenta su propia propuesta de 4 titulares y un suplente, sólo coincidente en el primer candidato con la anterior.

En el orden del día del Pleno del Congreso de 22 de noviembre se incluye la propuesta de nombramiento de candidatos; al inicio de la sesión, la Presidenta anuncia que la Comisión Consultiva de Nombramientos no había emitido criterio en relación con la propuesta de nombramiento de vocales juristas, por lo que declara decaído el punto del orden del día.

Los medios de comunicación nos informan de lo ocurrido: se filtra un acuerdo PP-PSOE sobre el candidato a Presidente del CGPJ y del Tribunal Supremo, con el consiguiente escándalo, seguido de la difusión de un mensaje de whatsapp del portavoz del Grupo Popular en el Senado que pone en entredicho la independencia de la Sala de lo Penal del Tribunal Supremo que había de juzgar a las autoridades catalanas sobre el proceso de independencia, aparentemente para apaciguar a los senadores de su Grupo sobre los candidatos a proponer en dicha Cámara. El supuesto candidato a Presidente del Tribunal Supremo (Presidente de la citada Sala), en un comunicado difundido el día 20 de noviembre, expresa su «decidida voluntad de no ser incluido, para el caso en que así fuera considerado, entre los candidatos al puesto de Presidente del Tribunal Supremo y del CGPJ». Por su parte, el PP rompe el pacto de renovación del Consejo: la portavoz del Grupo Popular en el Congreso presenta un escrito de esa misma fecha en el que manifiesta su voluntad de retirar su firma del escrito de propuesta de candidatos de vocales juristas.

Conclusión: otra renovación fallida, aunque esta vez la estrategia pasara por recurrir al viejo sistema de cuotas entre los dos grupos mayores, que juntos reúnen la mayoría constitucionalmente exigida, sin contar con que no sólo ha cambiado la composición del Congreso, sino también la sensibilidad pública sobre el tema.

El resultado, el tradicional al que estamos acostumbrados: la prórroga de los vocales anteriores, incluido el Presidente, hasta que lleguen a designarse los nuevos, ya en otra legislatura: habrán de pasar al menos seis meses más, en el supuesto de que los acuerdos para la renovación sean rápidos, lo que no es de presumir.

\section{Consejo de Seguridad Nuclear}

El mismo día en que el Presidente del Gobierno anuncia que disolverá las Cámaras para celebrar elecciones el 28 de abril, el Consejo de Ministros aprueba

73 En el Senado, el plazo se abre el 3 de octubre y es ampliado hasta el 26 de noviembre. 
un Acuerdo en virtud del que se comunica al Congreso de los Diputados la propuesta de nombramiento de cuatro consejeros del Consejo de Seguridad Nuclear.

Conforme al artículo 5. 2 de la Ley 15/1980, de creación del Consejo de Seguridad Nuclear, el Presidente y los Consejeros «serán nombrados por el Gobierno, a propuesta del Ministro de Industria, Turismo y Comercio, previa comparecencia de la persona propuesta para el cargo ante la Comisión correspondiente del Congreso de los Diputados, en los términos que prevea el Reglamento del Congreso. El Congreso, a través de la Comisión competente y por acuerdo de los tres quintos de sus miembros, manifestará su aceptación o veto razonado en el plazo de un mes natural a contar desde la recepción de la correspondiente comunicación. Transcurrido dicho plazo sin manifestación expresa del Congreso, se entenderán aceptados los correspondientes nombramientos».

Dado que la disolución de las Cámaras tendría lugar antes de que se cumpliera el mes natural de plazo para que el Congreso expresara por tres quintos su aceptación o veto razonado a las personas propuestas a través de la Comisión competente, ante la que habían de comparecer, se planteó si podría aplicarse el inciso final del precepto transcrito, según el cual, transcurrido el plazo sin manifestación expresa del Congreso, se entenderán aceptados los correspondientes nombramientos.

Con independencia de los efectos en la composición que el nombramiento pueda tener o de la procedencia política de las propuestas, la cuestión no es fácil de resolver desde un punto de vista jurídico parlamentario. Cabría pensar que la comunicación no puede producirse una vez la Cámara disuelta, porque no existe comisión competente del Congreso — las competencias de la Diputación Permanente son tasadas - para manifestarse sobre la propuesta, luego habría que esperar —incluso si se envía durante la disolución- y no comenzar a computar los plazos hasta la constitución de la nueva Cámara. No obstante, existe algún precedente en contra de esta opinión, que no es compartida por todos.

Pero la comunicación se realiza antes de la disolución, bien es verdad que cuando esta ha sido anunciada ya para diecisiete días después. La Cámara está activa, aunque el anuncio haya paralizado muchas iniciativas. La Comisión podía celebrar las comparecencias, que fue lo que de hecho ocurrión ${ }^{74}$. De otra parte, la no reunión podría interpretarse como obstruccionismo, si se diera carácter preceptivo a la emisión de aceptación o veto parlamentario. En todo caso, la Ley no atribuye a la falta de aceptación o veto por la mayoría requerida el efecto de impedir el nombramiento, sólo habrá de esperar el Gobierno a que transcurra un mes desde la recepción de la propuesta. El criterio que parece haber imperado es entender que la disolución no afecta al transcurso del plazo ${ }^{75}$. Ante las protestas

74 El 27 de febrero de 2019 se reúne la Comisión de Transición Ecológica del Congreso para la comparecencia de los candidatos propuestos. La votación, con el abandono de la sesión de algún grupo parlamentario, no alcanza la mayoría de tres quintos necesaria para la aceptación o el veto (Diario de Sesiones n. ${ }^{\circ} 744$ ).

75 Los ceses y nombramientos de Presidente y Consejeros del CSN se aprueban por Reales Decretos 224 a 230/2019, de 29 de marzo, publicándose en el BOE del día siguiente. 
y anuncio de recurso de amparo formulados por el Grupo Popular, es posible que sea el Tribunal Constitucional quien resuelva las dudas.

Se ha calificado, al principio del apartado, este último asunto en materia de designación de cargos de incidente que merece un comentario. La razón es que, una vez más, se encuentran en posiciones opuestas Gobierno y oposición, incluso en aquellos casos en los que la intervención parlamentaria y las mayorías exigidas pretenden - aunque sea por la que creíamos extinta vía de las cuotas- que vayan de la mano.

\section{EPILOGO: TURBULENCIAS DURANTE LA DISOLUCIÓN Y RESULTADOS ELECTORALES}

Un largo periodo preelectoral que abarca varios tipos de elecciones separadas por un mes de las generales (por primera vez tan corto espacio de tiempo), aporta novedades. La Instrucción 3/2019 de la Junta Electoral Central alarga considerablemente la prohibición de campañas institucionales e inauguraciones en periodo electoral (art. 50 LOREG) para los Gobiernos y autoridades autonómicas y municipales, al entenderlos afectados también por el primer proceso $^{76}$, sobre la base de que el principio de neutralidad debe ser absoluto durante cualquier periodo electoral, con independencia del proceso electoral convocado.

Ya nos hemos referido a la impugnación ante la JEC de las ruedas de prensa posteriores a los anunciados «viernes sociales» del Consejo de Ministros, con resultado adverso para los denunciantes (supra, nota 25). Mayor éxito tuvo la reclamación planteada por los representantes generales del Grupo Popular contra la Vicepresidenta del Gobierno y Ministra de la Presidencia, Relaciones con las Cortes e Igualdad, «por la publicación y difusión en las redes sociales y páginas web de las Administraciones Públicas, de críticas electorales y partidistas en relación con la lucha por la igualdad», que fue estimada por la JEC el 21 de marzo de 2019, aun cuando los mensajes en la cuenta de twitter oficial del Ministerio de la Presidencia habían sido retirados una vez denunciados. La JEC entiende que tal difusión supone una vulneración del principio de neutralidad de los poderes públicos que dimana del artículo 50.2 LOREG y que la reincidencia le obliga a apercibir a la Vicepresidenta del Gobierno de la posibilidad de que se incoe un expediente sancionador, con arreglo al artículo 153.1, en caso de que se repitan nuevos quebrantamientos en el futuro ${ }^{77}$.

76 Del mismo modo se entiende afectada la prohibición de realizar actos de campaña o propaganda electoral referidos a otras elecciones los días de reflexión y votación en las elecciones al Congreso y al Senado, o la publicación de encuestas referidas a otras elecciones en los cinco días anteriores a aquellas.

77 Acuerdos similares de estimación parcial, sin medidas sancionadoras, se adoptaron por la JEC el 4 de abril de 2019 respecto de reclamaciones de los representantes generales del PP contra la Ministra de Justicia, por la difusión de un vídeo con la intervención del Presidente del Gobierno en el acto de 
Cambiando de tercio, difundido por los medios de comunicación el contenido de un informe jurídico en sentido discutible sobre la competencia de la Diputación Permanente del Congreso (y del Senado) para tramitar los proyectos de ley resultantes de la convalidación de decretos-leyes de conformidad con los artículos 78 y $86 \mathrm{CE}^{78}$, tal tramitación afortunadamente no ha llegado a materializarse, dado que la votación sobre la tramitación ha resultado siempre negativa. Destaquemos no obstante que la Diputación Permanente convalida 3 decretos-leyes adoptados durante el periodo de disolución de las Cámaras (más otros 3 aprobados con anterioridad), número no excesivamente elevado si lo comparamos con otras legislaturas, que hemos recogido supra en nota 25.

A una agitada campaña electoral suceden unas elecciones con un resultado que revalida al Presidente del Gobierno surgido de la moción de censura, en cuanto su partido casi duplica en escaños al siguiente en el Congreso y lo consigue en el Senado ${ }^{79}$, a lo que contribuye en gran medida la división de la derecha en tres opciones. Se confirma también el fin del bipartidismo y la consiguiente fragmentación del Congreso, Cámara en la que llegan a formarse siete grupos parlamentarios, además del mixto ${ }^{80}$ : hace diez años, PP y PSOE se repartían 21 millones y medio de votos ${ }^{81}$. En 2019, con una alta participación $(75,75 \%$ frente a 66,48\% en 2016), son cinco partidos de ámbito nacional los que suman 22 millones y medio de votantes y 312 escaños (89\%) en el Congreso.

presentación de la campaña electoral del PSOE en medios y redes sociales de titularidad pública, y contra el Presidente del Gobierno por alusiones a logros en la página institucional de Presidencia del Gobierno y perfil institucional de twitter. La JEC se convirtió también en protagonista durante la campaña por sus decisiones, entre otras: en relación con los debates entre candidatos, al excluir a Vox de un debate a cinco en cadena nacional privada, de conformidad con la normativa vigente, estimando los recursos presentados por los grupos más representados CCa, PNV y Junts (Ac. 16/04/19), criterio aplicado parcialmente también en las elecciones municipales y autonómicas al nuevo partido abanderado por M. Carmena e I. Errejón (la consideración de nuevo partido conlleva consecuencias en cuanto a espacios de publicidad gratuita, bloques de informativos en medios públicos y debates); autorizando o denegando la participación en actos electorales de candidatos independentistas en situación de prisión provisional; y, ya respecto de la siguiente convocatoria electoral, por sus decisiones de exclusión de candidaturas a las elecciones europeas. Puede verse un comentario de algunos de estos acuerdos en J. J. Solozábal, «La Junta Electoral Central y sus decisiones», El País 7 mayo 2019).

78 Las posturas doctrinales que aplican una interpretación literal o bien sistemática y lógica (que comparto) de los preceptos constitucionales, respectivamente en J.J. LAVILLA RuBIRA, «Artículo 78: Las Diputaciones Permanentes del Congreso y del Senado», en O. Alzaga Villaamil, dir., Comentarios a la Constitución Española de 1978, tomo VI, Edersa, Madrid, 1998, pp. 742 y ss., e I. Astarloa Huarte-MendicoA, «Artículo 86: Decretos-leyes», en la misma obra, tomo VII, pp. 244 y ss.

79 Congreso: PSOE, 123 escaños; PP, 66 (1 con Foro); Cs, 57; UP y coaliciones, 42; Vox, 24; ERC, 15; JuntsxCat-JUNTS, 7; PNV, 6; EH Bildu, 4; CCa-PNC, 2; NA+, 2; Compromis, 1; PRC, 1. Senado: PSOE, 121; PP, 56; ERC, 11; PNV, 9; CS, 4; Na+, 3; JuntsxCat-JUNTS, 2; ASG, 1; EH Bildu, 1.

80 Integrado, tras recursos y acuerdos de la Mesa, por 18 miembros: 7 JuntsxCat, 4 EH Bildu, 2 Navarra Suma, 2 CCa, 1 Compromís, 1 PRC y Oriol Junqueras (ERC).

$81 \mathrm{La}$ suma de los votos de PSOE y PP en las elecciones generales de 2008 alcanzó 21.567.345 (20.661.654 en 2004). El descenso se inicia en 2011: 17.804.573 votos. En 2016, serían 13.385.082 (55.64\%); en 2019, con una participación mayor, 11.836 .778 (45,38\%). Fuente: Ministerio del Interior. En los resultados publicados por la JEC (BOE 30 mayo 2019) la suma alcanza 11.886.795. 


\section{CONCLUSIONES: DE CARA AL FUTURO}

Se ha calificado de destructiva la moción de censura aprobada ${ }^{82}$, en el sentido de que su único objetivo era cesar al Presidente del Gobierno, sin que existiera un programa de gobierno, que tampoco se pudo conseguir acordar ya en el poder: «con este punto de partida, como era de prever, gobernar resulta imposible ${ }^{83}$. Y, en efecto, el Gobierno surgido de un apoyo multicolor, que se ha pretendido ridiculizar con el sobrenombre de Frankenstein, ha tenido un brevísimo mandato de apenas nueve meses. Concluye tras el rechazo de los presupuestos para 2019 con una disolución anticipada — que tal vez nadie más quería, dado el resultado incierto de las siguientes elecciones - debida en suma a la fragilidad del pacto que llevó a la moción de censura supuestamente constructiva y claramente no estable ${ }^{84}$, sobre todo por las interferencias del procès catalán ${ }^{85}$. Que las elecciones hayan reforzado al partido vencedor en la moción de censura constituye un ingrediente más para reflexionar sobre los efectos que provoca en el panorama político la investidura del Presidente de un Gobierno que nació débil en cuanto a número de escaños, por mucho que se negara a contemplar la moción como meramente instrumental para una convocatoria inmediata de elecciones ${ }^{86}$.

Como en el análisis de la primera parte de la legislatura, los acontecimientos recogidos en este trabajo no pretenden conformar una crónica: se aportan como ejemplos de la singularidad de una legislatura partida en dos — que a su vez rompe con todos los esquemas anteriores- que exigen nuevas interpretaciones y aplicaciones de la Constitución y de los Reglamentos de las Cámaras, y que afectan intensamente a las relaciones entre el ejecutivo y el legislativo.

A lo largo de este trabajo, al igual que en la primera parte de la XII legislatura, hemos constatado una paralización casi total de la función legislativa de las

82 F. De Carreras, «La demolición ha empezado», cit.; F. Simón YARZA, «De la investidura convulsa a la moción de espíritu destructivo», cit., p. 123: en este sentido, a diferencia de lo ocurrido en Weimar, en la moción española «es la letra de la Constitución la que se ha empleado en contra de su espíritu», lo que se manifiesta en la ausencia de un programa positivo, la heterogeneidad de fuerzas políticas y los fundamentos heterogéneos de la coincidencia (disparidad) de motivos, expresada en las intervenciones parlamentarias de los portavoces, así como en la elusión de la responsabilidad de la moción, que se imputaba al Presidente censurado por no dimitir (pp. 124-125).

83 F. De Carreras, «La demolición ha empezado», cit.

84 En palabras de R. Blanco VALDÉs, hemos pasado del bipartidismo imperfecto a la perfecta ingobernabilidad ( $\mathrm{El}$ año que vivimos peligrosamente: del bipartidismo imperfecto a la perfecta ingobernabilidad», REDC, n. ${ }^{\circ} 109,2017$, pp. 63 y ss.): la gobernabilidad ha sido una de las señas de identidad de la política española posconstitucional, la estabilidad, más que ninguna otra, ha sido la característica definidora de la política española desde el final de la transición (p. 66).

85 Sobre las dificultades de fundamentar la gobernabilidad en un doble tipo de fuerzas políticas, estatales y territoriales, sin que entre ellos se haya forjado nunca un proyecto político común de Estado, A. PorRAS NADALES, «La función de gobierno en la Constitución española, cuarenta años despúes», cit., pp. 119 y ss.

86 La comparación de la oferta de moción instrumental propuesta por Ciudadanos con las cuestiones de confianza instrumentales planteadas en Alemania avaladas por el Tribunal Constitucional Federal, en F. SIMÓN YARZA, «De la investidura convulsa a la moción de espíritu destructivo», cit., pp. 132-133. 
Cortes Generales, con un número mínimo de leyes aprobadas (39) que ni siquiera permiten cumplir con obligaciones europeas; un uso del decreto-ley, sobre todo tras el cambio de gobierno - pues el primero no contaba con la convalidación del Congreso - para desarrollar los compromisos pactados que no pueden aprobarse por ley o a través de medidas presupuestarias. Hemos visto también la potenciación de instrumentos de control e indirizzo, en particular las reprobaciones de ministros en la primera parte de la legislatura o las proposiciones no de ley en comisión, como medio de hacer visible la nueva oposición fragmentada; la facilidad de creación de las comisiones de investigación, frente a la dificultad para que lleguen a término consensuando unas conclusiones; ciertos esfuerzos del Senado por adquirir un mayor protagonismo como Cámara de oposición mayoritaria al Gobierno salido de la moción de censura; intentos fallidos o ensayos frustrados de nombramientos a la antigua y a la nueva usanza...

En definitiva, una legislatura estéril en el sentido de poco productiva, no ya cuantitativamente, sino en cuanto a avances en la adaptación a la nueva realidad: el fin del bipartidismo, que ha cedido el paso a un Parlamento fragmentado. No parece haber calado aún la cultura del pacto, pese a que en el seno de la Cámara sí han podido apreciarse adelantos en este sentido, pero con un cierto carácter vergonzante de cara al electorado, que — añadido al cortoplacismo en las decisiones- no pocas veces han hecho fracasar iniciativas útiles para la sociedad.

En política no existen las moralejas. A la intensa y novedosa aplicación de la Constitución y del Derecho parlamentario en los últimos años debería suceder el intento de afrontar una nueva legislatura con un espíritu distinto, pero el enconamiento electoral no permite predecir un cambio radical de actitudes que no conduzca a la polarización y la permanente confrontación y bloqueo ${ }^{87}$. A ello contribuye la — - según lo previsto- mayor fragmentación del Congreso salido de las elecciones del 28 de abril de 2019, con la irrupción de un quinto partido de ámbito nacional de tamaño «mediano» y el incremento en la representación de los partidos nacionalistas.

Aboguemos por que el «equilibrio de debilidades» entre Gobierno y Parlamento a que aludían Solé Tura y Aparicio ${ }^{88}$ como riesgo del carácter constructivo de la moción de censura y la correlativa búsqueda de la estabilidad gubernamental, no se convierta en la tónica permanente de nuestro futuro sistema político no bipartidista, ya que — auguraban— «el resultado de ello es el debilitamiento de ambas instituciones».

87 Los inicios de la XIII legislatura (sesión constitutiva, juramento, suspensión de parlamentarios en situación de prisión provisional) anuncian otro período conflictivo que sin duda deberá ser objeto de estudio. También merecerá una reflexión la actividad de «sudoku» y «cambio de cromos» posterior a las elecciones autonómicas y municipales, que suscitan la duda de si los pactos reflejarán la voluntad de los electores y tendrán como último objetivo el interés general.

88 J. Solé Tura y M. A. Aparicio Pérez, Las Cortes Generales en el sistema constitucional español, Tecnos, Madrid, 1984, p. 206. 


\section{POST SCRIPTUM}

En línea con las predicciones aventuradas más arriba, la fragmentación parlamentaria y la falta de acuerdo entre partidos impidieron la investidura de Presidente de Gobierno en la XIII legislatura, produciéndose, —estando en imprenta este trabajo_-, un intento fallido y, el 24 de septiembre de 2019, por segunda vez en nuestra historia la disolución prevista en el art. 99.5 CE. Con un largo periodo de Gobierno en funciones se reinicia el ciclo.

TITLE: Assessment of the constructive vote of no confidence in a fragmented parliament

ABstRACT: The adoption of a constructive vote of no confidence in Spain for the first time since the adoption of the Spanish 1978 Constitution has led to the change of political sign of the Government in the middle of the XII legislature or term, characterised by the fragmentation of the Congress of Deputies which has replaced the former nearly two-party system. The essay analyses the consequences of this change on the functioning and functions of Parliament and on the instability of a Government that has been in power for only nine months, taking stock of the period extending from the vote of no confidence to dissolution of Parliament, comparing it with the equally diffcult previous period and with other terms, to ultimately show how the end of the two-party system has influenced Government-Parliament relations in the Spanish parliamentary political system.

RESUMEN: La aprobación de una moción de censura en España por primera vez desde la aprobación de la Constitución ha supuesto el cambio de signo político del Gobierno a mitad de la XII legislatura, caracterizada por la fragmentación del Congreso de los Diputados que ha sustituido al cuasibipartidismo anterior. El artículo examina las consecuencias que la moción ha tenido en el funcionamiento y funciones del Parlamento y en la inestabilidad de un Gobierno que se ha mantenido en el poder apenas nueve meses, haciendo balance del periodo que se extiende de la moción de censura a la disolución, comparándolo con el periodo anterior asimismo dificultoso y con otras legislaturas, para en último término mostrar cómo el fin del bipartidismo ha influido en las relaciones Gobierno-Parlamento en nuestro régimen parlamentario.

KEY WORDS: Constructive vote of no confidence, fragmented Parliament, minority Government, Parliament's functions, Spanish Congress of Deputies, Spanish Parliament.

Palabras Clave: Moción de censura constructiva, Parlamento fragmentado, Gobierno en minoría, funciones de las Cámaras, Congreso de los Diputados.

FECHA DE RECEPCIÓN: 08.05.2019

FECHA DE ACEPTACIÓN: 29.07.2019 